\title{
Conversion of \\ Forest Residues to a Methane-Rich Gas
}

\author{
Phase Completion Report
}

March 1986

Prepared by Battelle Columbus Laboratories for Pacific Northwest Laboratory under Contract DE-AC06-76RLO 1830 with the U.S. Department of Energy

Pacific Northwest Laboratory Operated for the U.S. Department of Energy by Battelle Memorial Institute 


\title{
DISCLAIMER
}

This report was prepared as an account of work sponsored by an agency of the United States Government. Neither the United States Government nor any agency thereof, nor any of their employees, makes any warranty, express or implied, or assumes any legal liability or responsibility for the accuracy, compieteness, or usefulness of any information, apparatus, product, or process disclosed, or represents that its use would not infringe privately owned rights. Reference herein to any specific commercial product, process, or service by trade name, trademark, manufacturer, or otherwise, does not necessarily constitute or imply its endorsement, recommendation, or favoring by the United States Government or any agency thereof. The views and opinions of authors expressed herein do not necessarily state or reflect those of the United States Government or any agency thereof.

\author{
PACIFIC NORTHWEST LABORATORY \\ operated by \\ BATTELLE \\ for the \\ UNITED STATES DEPARTMENT OF ENERGY \\ under Contract DE-AC06-76RLO 1830
}

\begin{tabular}{|c|c|}
\hline \multirow{2}{*}{\multicolumn{2}{|c|}{$\begin{array}{l}\text { Printed in the United States of America } \\
\qquad \text { Available from }\end{array}$}} \\
\hline & \\
\hline \multicolumn{2}{|c|}{ National Technical Information Service } \\
\hline \multicolumn{2}{|c|}{ United States Department of Commerce } \\
\hline 5285 & \\
\hline \multicolumn{2}{|c|}{ Springfield, Virginia 22161} \\
\hline \multirow{2}{*}{\multicolumn{2}{|c|}{$\begin{array}{l}\text { NTIS Price Codes } \\
\text { Microfiche A01 }\end{array}$}} \\
\hline & \\
\hline \multicolumn{2}{|c|}{ Printed Copy } \\
\hline & Price \\
\hline Pages & Codes \\
\hline $007-025$ & $\mathrm{~A} 02$ \\
\hline 026.050 & A03 \\
\hline $051-075$ & A04 \\
\hline $076-100$ & A05 \\
\hline $107-125$ & A06 \\
\hline $126-150$ & A07 \\
\hline $157-175$ & $A D B$ \\
\hline $176-200$ & $A 09$ \\
\hline $201-225$ & A010 \\
\hline $226-250$ & A011 \\
\hline $251-275$ & A012 \\
\hline $276-300$ & $A 013$ \\
\hline
\end{tabular}


PNL - 5798-1

UC -610

CONVERSION OF FOREST RESIDUES

TO A METHANE-RICH GAS

PHASE COMPLETION REPORT

March 1986

Prepared by

Battelle Columbus Laboratories

for Pacific Northwest Laboratory under Contract DE-AC06-76RLO 1830

with the U.S. Department of Energy

Agreement $W-7405-E n g-92$ (Task 102)

Pacific Northwest Laboratory

Richland, Washington 99352 


\section{SUMMARY}

Th1s report, which was submitted to Pacific Northwest Laboratory in September 1978, describes the progress made during the first phase of a DOE program to 1nvestigate the use of varlous catalysts and methods of 1ncorporation for the gasification of forest residue materlals. Catalyst effectiveness was determined by measuring the gasification rate directly in a differential reactor that ut1lized approximately one gram samples and by gasifying approximately 10 to 20 gram samples in a batch-aollds fluld bed (BSFB to determine the effect of catalysts on product gas composition.

In addition to the bench-scale experimental work, the use of vartous gastfication systems was considered in light of the reactivity and physical characteristics of wood regidues. Finally, some preliminary process economic projections were made.

In order to provide the most readable and useful review of the work completed during this phase, this report wil sumarize results and concentrate on those thought to have the greatest process potential as well as present the maln features of the economic feasiblity study. The detalled process economic feasibility study will be published as an appendix to this report.

The work reported here on catalysis, gasification reactor concept development, and process economic feasibllity, though done on wood chips, applies to many other blomass materials. For example, blomass materials, whatever the1r origin, are very similar chemically and in gasification reactivity. They also share many physical characteristics that make their handiling in gasiflers difficult. For example, they usually have a low bulk density, are fibrous, and therefore tend to shred in fibrous strands rather than into particles. Therefore, the reactor system described in this report that allows excellent fluld1zation of wood chips should also be effective for agricultural residues and other forms of blomass.

The direct catalysis of wood should allow milder gasification conditions, 1mpart higher reactivity and/or improved product distribution, thereby reducing the overall costs of gasiflcation. Battelle has developed a novel technique for directly catalyzing coal by chemically incorporating CaO into the coal 
structure from an elevated temperature $\left(250^{\circ} \mathrm{C}\right)$ slurry. (1) CaO Incorporated in this fashion was found to be much more effective than physically mixed CaO. Therefore, a gubstantial portion of this work applied this technique for catalyzing wood. 


\section{CONTENTS}

PROGRAM OBJECTIVES $\ldots \ldots \ldots \ldots \ldots \ldots \ldots \ldots \ldots \ldots \ldots \ldots \ldots \ldots \ldots \ldots \ldots \ldots \ldots$

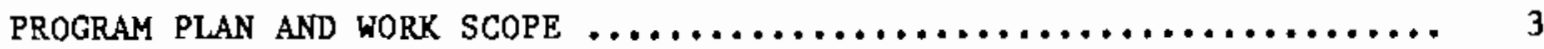

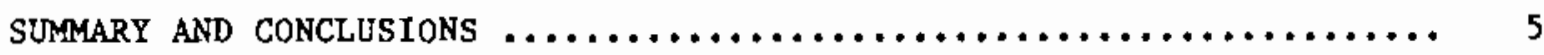

Catalyses and Gasification Properties .................. 5

Reactor Concept Development $\ldots \ldots \ldots \ldots \ldots \ldots \ldots \ldots \ldots \ldots \ldots \ldots \ldots, 6$

Process Economics $\ldots \ldots \ldots \ldots \ldots \ldots \ldots \ldots \ldots \ldots \ldots \ldots \ldots \ldots \ldots \ldots$

DISCUSSION OF RESULTS $\ldots \ldots \ldots \ldots \ldots \ldots \ldots \ldots \ldots \ldots \ldots \ldots \ldots \ldots \ldots \ldots$

Catalyt1c Treatment $\ldots \ldots \ldots \ldots \ldots \ldots \ldots \ldots \ldots \ldots \ldots \ldots \ldots \ldots \ldots \ldots$

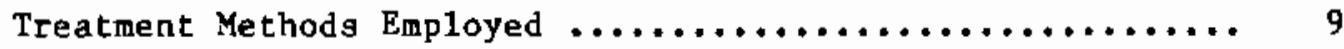

Catalysts Evaluated $\ldots \ldots \ldots \ldots \ldots \ldots \ldots \ldots \ldots \ldots \ldots \ldots \ldots \ldots$

Effect of Treatment on Gaslfication $\ldots \ldots \ldots \ldots \ldots \ldots \ldots \ldots \ldots \ldots$

Gasification Rate ............................ 14

Comparison of Slurry Impregnated and Dry Mixed Catalyst

Sygtems $-\mathrm{CaO}, \mathrm{Na}_{2} \mathrm{CO}_{3} / \mathrm{CaO}, \mathrm{Na}_{2} \mathrm{CO}_{3}$ and $\mathrm{NaOH} \ldots \ldots \ldots \ldots \ldots \ldots \ldots \ldots \ldots \ldots$

Soluble Catalystg - Calctum Acetate and Nitrate, Potassium,

and Sodfum Carbonates ................................ 20

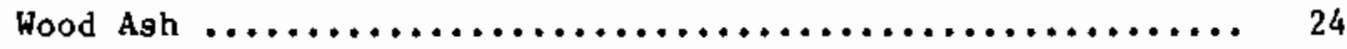

Mechanlsm of Catalytic Action $\ldots \ldots \ldots \ldots \ldots \ldots \ldots \ldots \ldots \ldots . \ldots 27$

Selection of the Most Promising Catalyst System Based on

Reactivity Enhancement .............................. 29

Effect of Wood Type and Properties on Gaslfication Rate ........ 29

Wood Type $\ldots \ldots \ldots \ldots \ldots \ldots \ldots \ldots \ldots \ldots \ldots \ldots \ldots \ldots \ldots \ldots \ldots \ldots \ldots$

Wood Particle Size $\ldots \ldots \ldots \ldots \ldots \ldots \ldots \ldots \ldots \ldots \ldots \ldots \ldots \ldots \ldots$

Gastfication Temperature ................................ 34

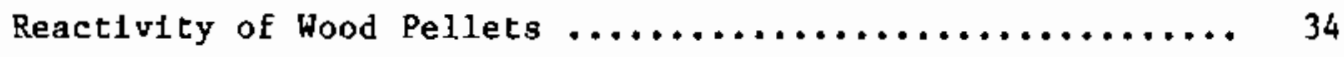


Product Distribution $\ldots \ldots \ldots \ldots \ldots \ldots \ldots \ldots \ldots \ldots \ldots \ldots \ldots \ldots \ldots, 38$

Experimental Varlables and Meagured Parameters .......... 38

REACTOR CONCEPT DEVELOPMENT $\ldots \ldots \ldots \ldots \ldots \ldots \ldots \ldots \ldots \ldots \ldots \ldots \ldots \ldots \ldots \ldots$

Reactor Throughput $\ldots \ldots \ldots \ldots \ldots \ldots \ldots \ldots \ldots \ldots \ldots \ldots \ldots \ldots \ldots \ldots, 50$

Utilization of Existing Gasification Reactor Systems ......... 52

Fluid Beds $\ldots \ldots \ldots \ldots \ldots \ldots \ldots \ldots \ldots \ldots \ldots \ldots \ldots \ldots \ldots \ldots \ldots \ldots \ldots$

"Moving"-Bed Reactors ........................ 54

Entrained Gastflers $\ldots \ldots \ldots \ldots \ldots \ldots \ldots \ldots \ldots \ldots \ldots \ldots \ldots \ldots$

The Multi-Solld Fluid-Bed Gasifier ................. 54

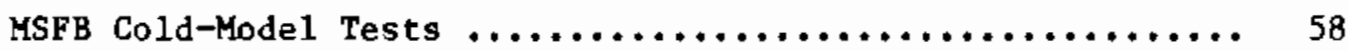

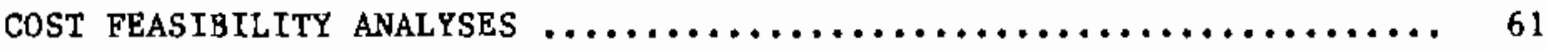

Intermediate Btu Gas $\ldots \ldots \ldots \ldots \ldots \ldots \ldots \ldots \ldots \ldots \ldots \ldots \ldots \ldots \ldots$. $6 \ldots \ldots$

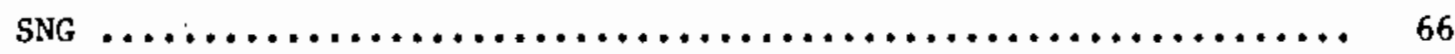

Estimation of Gas Price $\ldots \ldots \ldots \ldots \ldots \ldots \ldots \ldots \ldots \ldots \ldots \ldots \ldots \ldots$

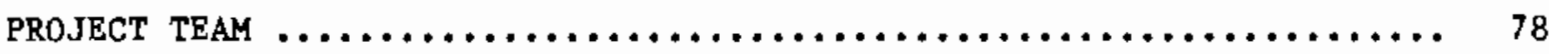

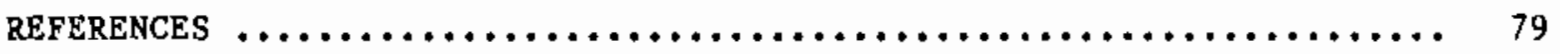


FIGURES

1. SCHEMATIC DIAGRaM OF THE ONE-Gallon AUTOCLAVE SYSTEM $\ldots \ldots \ldots \ldots \ldots 10$

2. TREATMENT PRODUCT WORK-UP PROCEDURE $\ldots \ldots \ldots \ldots \ldots \ldots \ldots \ldots \ldots \ldots \ldots$

3. EFFECT OF CaO CONCENTRATION ON GASIFICATION

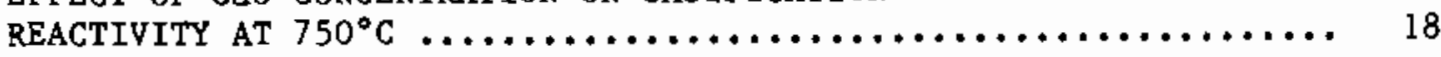

4. COMPARISON OF CATALYSES WITH $\mathrm{Na}_{2} \mathrm{CO}_{3}$ WITH $\mathrm{CaO}, \mathrm{Na}_{2} \mathrm{CO}_{3}-\mathrm{CaO}$ AND RAW WOOD, CATALYST/WOOD RATIO $=0.05$.

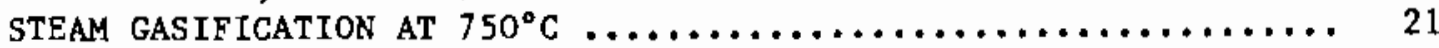

5. STEAM GASIFICATION OF SWEETGUM AT $750^{\circ} \mathrm{C}$. COMPARISON OF

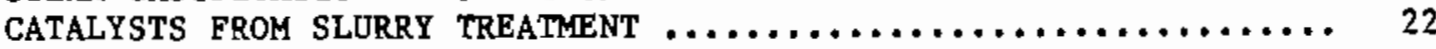

6. EFFECT OF $\mathrm{K}_{2} \mathrm{CO}_{3}$ /WOOD RATIO. STEAM GASIFICATION OF

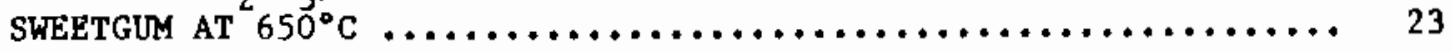

7. CATALYSIS WITH RECYCLE ASH. STEAM GASIFICATION OF OAK ....... 25

8. CATALYSIS WITH RECYCLE ASH. STEAY GASIFICATION

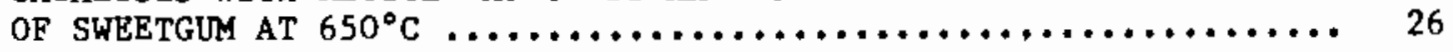

9. GASIFICATION OF ALKALI CATALYZED AND UNCATALYZED WOOD $\ldots \ldots \ldots \ldots \ldots$

10. TIME REQUIRED TO CONVERT 95 PERCENT OF THE WOOD AT $750^{\circ} \mathrm{C} \ldots \ldots . .30$

11. COMPARISON OF RAW WOOD STEAM GASIFICATION CONVERSIONS

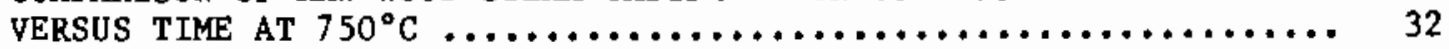

12. COMPARISON OF WOODS TREATED AT $210^{\circ} \mathrm{C}, 0.1 \mathrm{CaO} /$ WOOD FOR 1 HOUR. WATER/WOOD 6 , GASIFICATION AT $750^{\circ} \mathrm{C} \ldots \ldots \ldots \ldots \ldots \ldots . \ldots 33$

13. EFFECT OF WOOD PARTICLE SIZE, CaO/COAL $=0.05$, $210^{\circ} \mathrm{C}$ TREATMENT, WATER $/$ COAL $=6.0 \ldots \ldots \ldots \ldots \ldots \ldots \ldots \ldots \ldots \ldots \ldots \ldots$

14. STEAM GASIfICATION OF RAW OAK VERSUS TEMPERATURE $\ldots \ldots \ldots \ldots \ldots \ldots .36$

15. RESULTS OF STEAM GASIFICATION AT $750^{\circ} \mathrm{C}$. PELLETS AS RECEIVED AND CRUSHED TO $12 \times 30$ AND RAW WOOD FROM GUARANTY ........... 37

16. COMPARISON OF RAW WOOD AND PELLETS FROM BIOSOLAR CORPORATION STEAM GASIFICATION AT $750^{\circ} \mathrm{C} \ldots \ldots \ldots \ldots \ldots \ldots \ldots \ldots . \ldots \ldots$

17. TOTAL CARBON CONVERSION TO LIQUIDS VERSUS GASIFICATION TEMPERATURE AS A FUNCTION OF WOOD CATALYSTS $\ldots \ldots \ldots \ldots \ldots \ldots \ldots \ldots ., 44$ 
18. $\mathrm{H}_{2}$ /CO RATIO VERSUS GASIFICATION TEMPERATURE AS A

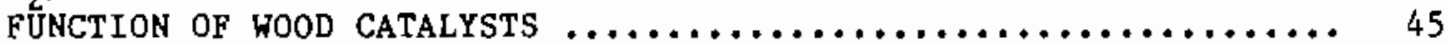

19. $\mathrm{CH}_{4}$ SELECTIVITY VERSUS GASIFICATION TEMPERATURE AS A FUNCTION OF WOOD CATALYSTS $\ldots \ldots \ldots \ldots \ldots \ldots \ldots \ldots \ldots \ldots \ldots \ldots \ldots \ldots, 47$

20. BTU YIELD VERSUS CARBON CONVERSION AS A FUNCTION OF

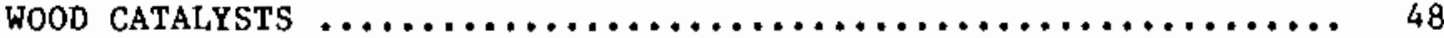

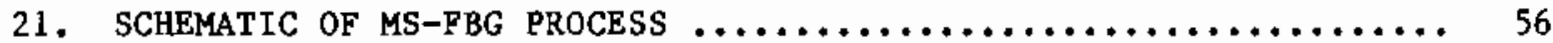

22. PROCESS FLOW DIAGRAM FOR INTERMEDIATE-BTU GAS FROM

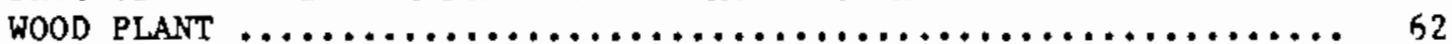

23. PROCESS FLOHSHEET FOR GASIFICATION OF FOREST RESIDUES AND CONVERSION TO SNG $\ldots \ldots \ldots \ldots \ldots \ldots \ldots \ldots \ldots \ldots \ldots \ldots \ldots \ldots \ldots \ldots \ldots, 67$

24. EFFECT OF PLANT SIZE, HOOD PRICE, GAS HEATING VALUE, AND GAS QUENCHING ON AVERAGE PRICE OF GAS FROM WOOD $\ldots \ldots \ldots \ldots \ldots \ldots \ldots \ldots$ 


\section{TABLES}

1. wOOS ANALYSES AND PARTIClE SIZE DISTRIBUTION $\ldots \ldots \ldots \ldots \ldots \ldots \ldots \ldots$ is

2. SUMMARY OF WOOD SOLUBILITY DURING SLURRY TREATMENT $\ldots \ldots \ldots \ldots \ldots \ldots 17$

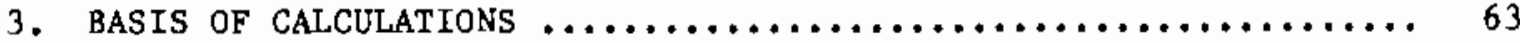

4. TOTAL PLANT INVESTMENT - SOO TPD WOOD CHIPS $\ldots \ldots \ldots \ldots \ldots \ldots \ldots .64$

5. TOTAL CAPITAL REQUIREMENT $\rightarrow 500$ TPD WOOD CHIPS $\ldots \ldots \ldots \ldots \ldots \ldots .64$

6. ANNUAL OPERATING COSTS -500 TPD HOOD CHIPS ............... 65

7. MATERIAL BALANCE FOR 5000 TPD HIGH BTU GASIFICATION PLANT $\ldots \ldots \ldots 68$

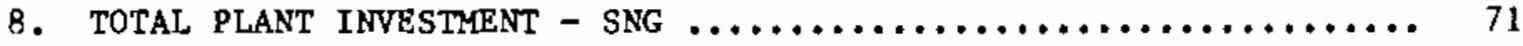

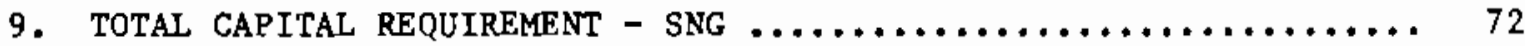

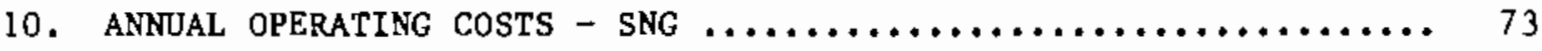

11. CAPITAL REQUIREMENTS AND ANNUAL OPERATING COST SUMMARY

PLANT PRESSURE $=100$ PSIG EXCEPT WHERE NOTED ............ 74

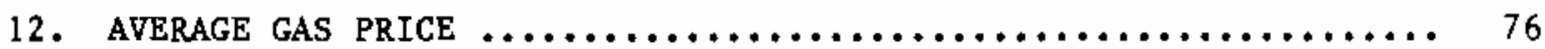


PROGRAM OBJECTIVES

The overall purpose of th1s program is to 1mprove the technology and the economics of gasifying wood residues by the use of direct gasification catalysts and the application of a unique gasification reactor system. Specific objectives of the first phase of the program were:

(1) To determine the reactivity increase and shift in gaseous product distribution brought about by catalysts.

(2) To evaluate the potential of varlous gasification reactor concepts for commercial-sized gasification plants.

(3) To develop process flowsheets for technlcal and economic evaluation. 


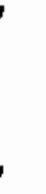




\section{PROGRAM PLAN AND WORK SCOPE}

The program plan called for the catalyzation of wood chips by chemical Incorporation of $\mathrm{CaO}$ as described above and then testing the catalyzed wood in two types of bench-scale gasiflcation units. The two key parameters that would be measured in these units to determine the effectiveness are the gasification rate and the shift in gaseous yield and product distribution brought about by catalysis. Gasification rates were directly measured in a small pressurized Thermogravimetric Analyzer (TGA) which is described in detatl later. Gas ylelds and product distributions were measured in a small, batch-solids, fluld-bed reactor whlch employed approxImately $20 \mathrm{gm}$ samples.

In order to Improve wood catalysis and to compare chemically incorporated catalysts with those that are simply physically mixed in with the wood, additional experfments were conducted to test different catalytic materials as well as methods of catalyst 1ncorporation.

Based on the reactivity measurements, exploratory cold-model experiments and conceptual reactor designs, the potential problems in utflizing wood residues in conventional gasification systems as well as the throughput limitations in such systems were assessed. The applicability of a Battelle-developed reactor system was then tested in the cold model. These results were then used to develop a conceptual design for a commercial gasifier and heat and material balances were developed to allow the specification of a flowsheet for an integrated process gasifying wood resldues.

The flowsheet was used as the basis for doing a cost feasiblitty analyses for vartous stzed plants and the sensitivity of gas price to plant size and the price of wood restdues determlned. In addition to evaluating the economics of producing an intermediate-Btu gas (used both hot without quenching and cold) a single case was costed for producing an SNG for a 5000 tpd (oven dry) plant.

Based on the results of the f1rst phase of this program, recommendations for further development were made. 


\section{SUMMARY AND CONCLUSIONS}

Several potential catalytic systems were evaluated in the benchscale reactor systems. Of all the catalytic materlals tested, wood ash seems like the best candidate for further evaluation. However, further experiments should be conducted in a continuous reactor system where particle heat-up rates and gas compositions are approximately equivalent to what will exist in a commerclal gasifier.

Injection of wood chips into a fluidized bed of coarse alumina particles ( 8 mesh) provided a mafor improvement in contacting over utilizing the wood chips alone. Addition of an entrained sand phase improved contacting even more. Thus the concept proposed is to use this technique with the entralned sand providing the heat for gasification. In addition, this socalled multi-solid gasffier can operate at the high gas velocities required to take advantage of the hlgh gasification reactivity of even uncatalyzed wood.

The eçonomic feasibility study indicates that an intermedlate-Btu gas can be produced in reasonably sized ( 1000 tpd) gasification plants at a price competitive with other supplemental energy such as No. 2 fuel oil or LNG.

Specific conclustons are tremized below.

\section{Catalyses and Gasification Properties}

- Several materials were catalytic towards wood gasification but based on cost and availability, wood ash seems like the best candldate for further evaluation.

- The method of catalyst application is not critical and, in a commercial application, a wood ash solution could be applied to the chips as they move along a conveyor.

- All the catalysts tested were promoters of the water gas shift reaction. However, they did vary in effectiveness toward the water-gas shift. 
- The originally proposed high-temperature slurry treatment to chemically incorporate calcium ions was not any more effective than other methods of application. In addition, it imposed penalties of wood solubility and high water requirements and these penalties would not be balanced by the reduction in gasifier temperature or enhancement of gasification rate.

- The gasification rate of even uncatalyzed wood is extremely high making compact reactors possible.

- Catalytic treatment brought about approximately the same degree of improvement in both hard woods and soft woods.

\section{Reactor Concept Development}

- In order to exploit the high reactivity of even uncatalyzed wood w11 require gasiflers operating at higher gas velocities than "conventional" systems. For example, based on the gasification rates measured, it is calculated that a gas velocity of $20 \mathrm{ft} / \mathrm{sec}$ would be required in order for the reactor throughput to be limited by the reactivity of the wood.

- Cold model tests indicated that wood chips alone are very difficult to fluldize. Interlocking of chips caused them to behave as slugs and/or create low pressure drop channels through which most of the gas flowed.

- Contacting difficulties could be overcome by Introducing the chips into a fluid bed of alumina particles and a further improvement in fluldization was achieved by the Introduction of an entrained sand phase which completely eliminated slugging.

- The only existing gasification reactor system that would allow the direct utflization of wood is the entrained gasifier. However, the cost of grinding vood to an entrainable powder would 1mpose a severe economic penalcy. 
- The proposed gasification reactor concept is based upon introducing the wood into a fluidized bed of solids which may either be Inert particles like the alumina or a methanation catalyst that can tolerate the sulfur levels anticipated. Heat for the gaslfication reaction would be supplied by the entrained phase - probably sand - which would reclrculate between the gasification reactor and a combustor where 1 t would be heated by burning char frot the gasifier.

\section{Process Economics}

- An 1ntermediate-Btu gas can be produced in reasonably sized (1000 tpd) plants and sold at a price competitive with other clean fuels such as LNG and No. 2 heating oil.

- The cost of wood 1s one of the most critical cost parameters. Therefore, to achieve attractive economics, It is 1mportant to be able to handle the wood product with ofinimal preparation.

- The extremely low sulfur content of wood eliminates the need for gas cleaning and allows the direct utilfzation of the hot gas which results in considerable cost savings. 
+
+ 


\section{DISCUSSION OF RESULTS}

\section{Catalytic Treatment}

Treatment Methods Employed

H1gh-temperature Slurry Treatment. The 1nit1al approach to catalytic treatment was based on the chemical incorporation of calcium ions into the wood structure. This method was tried because our work with coal had demonstrated that calcium chemically incorporated was more effective than physically incorporated calcium.

The equipment set up for chemical incorporation of the calcium into the wood is shown in Figure 1. The experimental procedure is described below.

(1) Charge prescribed amounts of wood, CaO and water into autoclave.

(2) Expel overhead air in the autoclave by purging the autoclave with nitrogen three times.

(3) Heat up the autoclave to a desired temperature and maintain for a prescribed reaction time.

(4) After cooling the autoclave to about $90 \mathrm{C}$, depressurize the autoclave, measure the amount of the product gas and obtain a gas sample for analysis in a GC.

(5) Filter the solid/11quid mixture.

(6) Recombine proportional amounts of the filtrate and the wet filter cake. Evaporate the sIurry to dryness to obtain a solid end product. Obta1n chemical analysis of this product.

(7) Dry filter cake in a vacuum oven.

(8) Determine $\mathrm{PH}$ value and measure the dissolved solid in the filtrate.

A sketch of the sample work-up procedure is shown in Figure 2. 


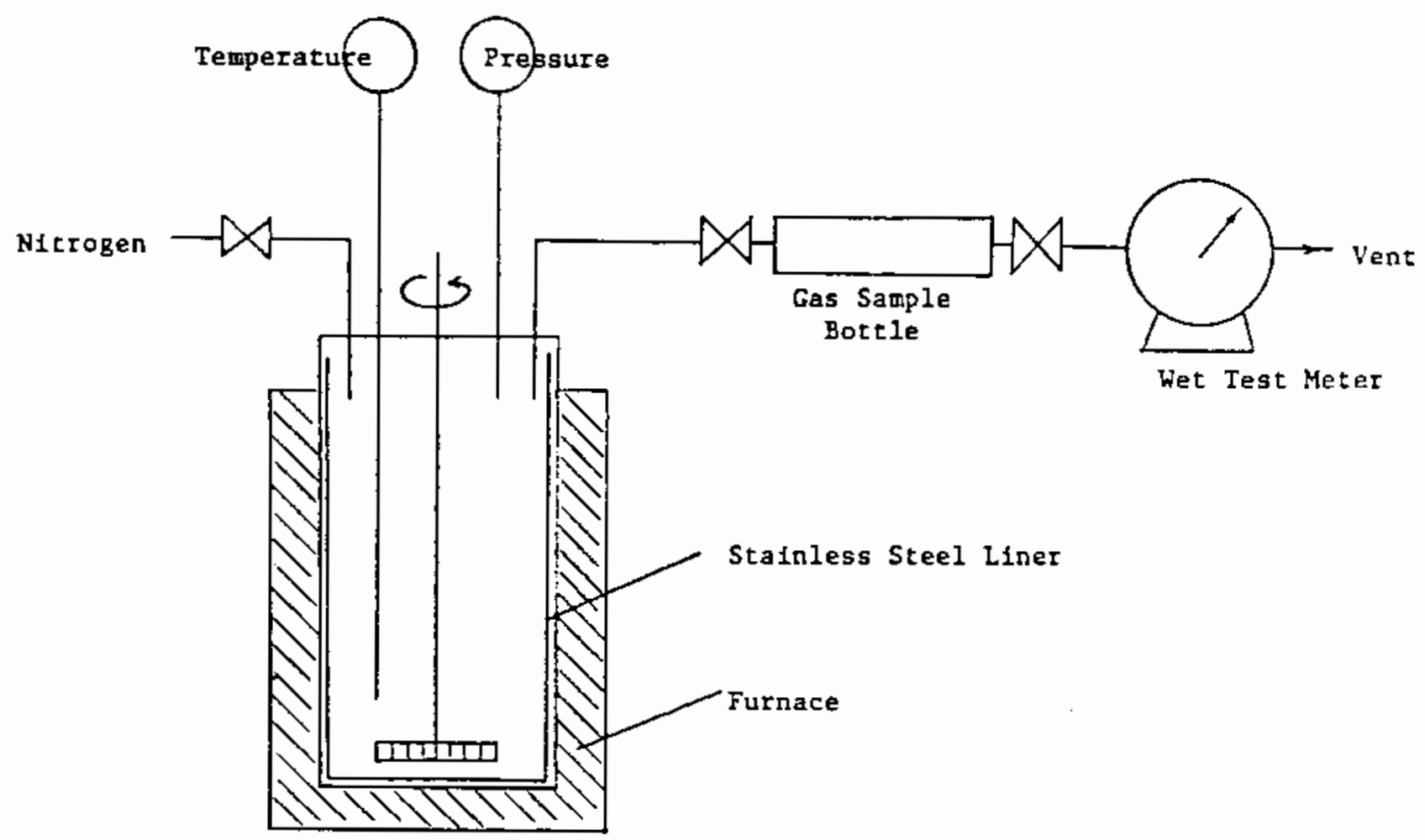

1-gallon Autoclave

FIGURE 1. SCHEMATIC DIAGRAM OF THE ONE-GALLON AUTOCLAVE SYSTEM 


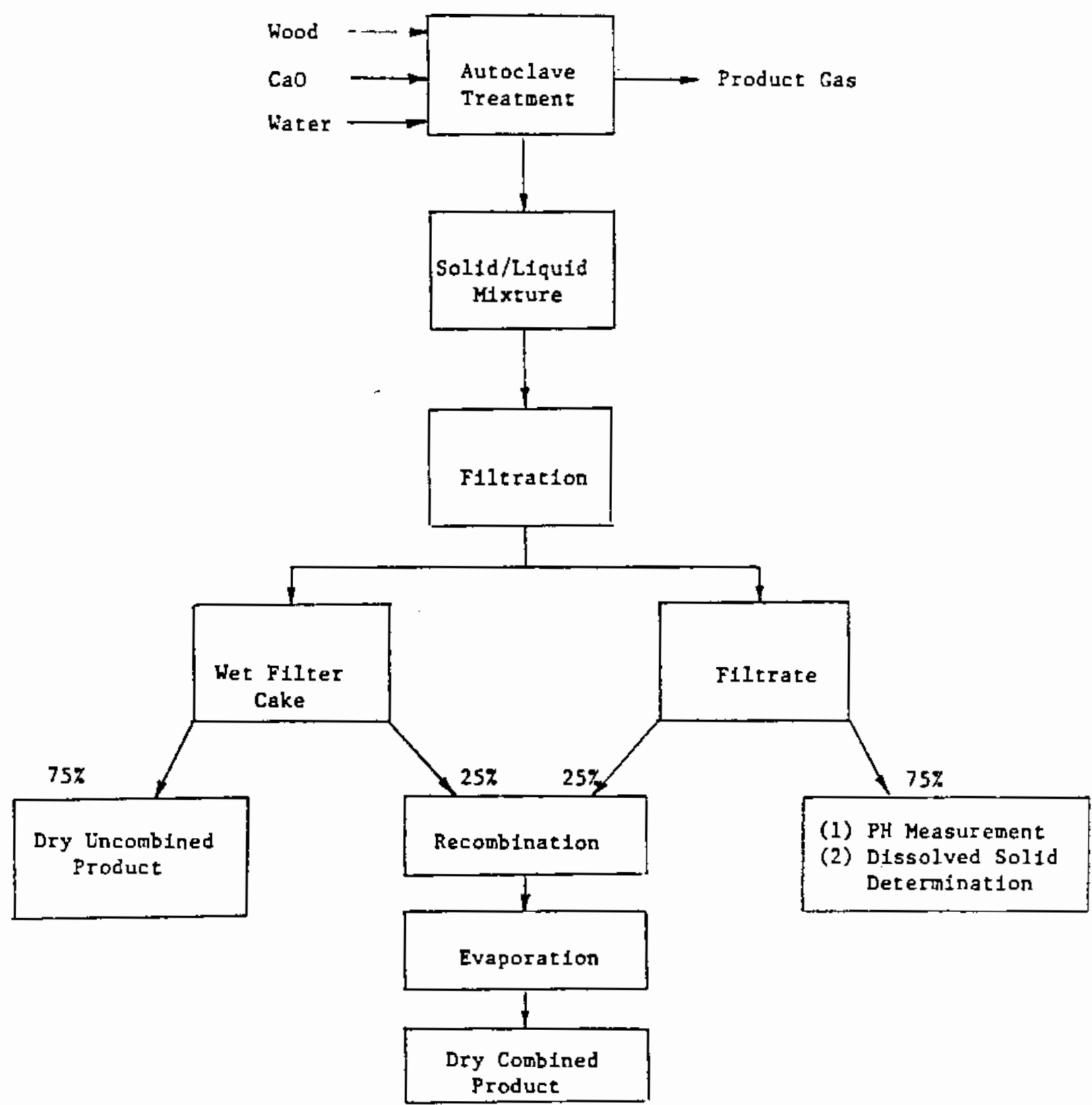

FIGURE 2. TREATMENT PRODUCT WORK-UP PROCEDURE 
The final product used for gasification testing in most instances was the combined product shown in Flgure 2 because this would simulate the product of a treatment process with direct drying of the slurry which represents the simplest integration of treatment with gasification. In addition, this method of operation would recover the wood solubllized.

The chemfcal incorporation of calcium was achleved by treating the carbonaceous feed in a heated slurry (approximately $200 \mathrm{C}$ ) for a few minutes residence time. However, as w1ll be discussed, there were some drawbacks applying this technique to wood that were not compensated for by the increase in gasification reactivity actually achleved. These drawbacks were the high water/wood ratio required for slurrying the wood and, to a lesser extent, the solubility of the wood in the hot slurry.

For the above reasons, the alternate means of catalyzing the wood discussed below were evaluted.

Ambient Treatment with Soluble Catalysts. The wood was slurried In an aqueous solution of water soluble catalyst at $6: 1$ water/wood ratio and usually a 1.1:1 catalyst/wood ratio for 10 minutes at room temperature. The solution was filtered to remove most of the catalyst and water.

The wood was then dried in a vacuum oven overnight at $60 \mathrm{C}$, under nitrogen. In two of the experiments with $\mathrm{Ca}\left(\mathrm{NO}_{3}\right)_{2} \cdot 4 \mathrm{H}_{2} \mathrm{O}$ as the catalyst part of the wood was heated at 180 and $210 \mathrm{C}$ in an autoclave for 60 minutes.

Solution Spraylng. Th1s method, like the room temperature slurry, was only used with water soluble catalysts. The wood was sprayed with an aqueous solution of catalyst. Varlations of this technique have included dry mixing the wood with catalyst and then spraying with water, followed by drying of the mixture or gasification of the wet catalytically treated wood. All of these variations result in essentially the same reactivity.

Dry Mixing. In this method, the catalyst and wood were wixed together dry. In order to help hold the catalyst in place, the catalyzed wood samples were IIghtly pelletized before gasification. 


\section{Catalysts Evaluated}

The following catalytic agents applied as shown were evaluated during the study.

\begin{tabular}{|c|c|}
\hline $\mathrm{CaO}$ & - High-temperature slurry and by dry mixing \\
\hline $\mathrm{Na}_{2} \mathrm{CO}_{3}$ & - High-temperature slurry \\
\hline $\mathrm{Na}_{2} \mathrm{CO}_{3} / \mathrm{CaO}$ & High-temperature slurry \\
\hline Ca acetate & - Ambient solution \\
\hline $\mathrm{Ca}\left(\mathrm{NO}_{3}\right)_{2}$ & Ambient solution \\
\hline $\mathrm{K}_{2} \mathrm{CO}_{3}$ & - Ambient solution \\
\hline Wood ash & - Ambient solution and by spraying \\
\hline
\end{tabular}

\section{Effect of Treatment on Gasification}

As mentioned in the previous section, the effectiveness of catalytic treatment was determined by measuring its effect on gasification rate and on product distribution. In general, total conversions in the batchsolids fluld-bed (BSFB) were lower than those anticlpated in the TGA expertments. In addition, the rating of catalyst effectiveness depended, to some extent, on the gasification system. Possible causes for the differences noted between the two reactor systems are:

- Gas composition - BSFB more closely approximates continuous gastfier

- Heat-up rate - TGA more closely approximates continuous gasifier.

Therefore, in order to generate reliable process evaluation data, continuous experiments should be conducted. For screening purposes and In the absence of continuous data, the assumption is that the TGA experiments reflect more accurately the rate enhancement while the BSFB is a reasonable Indicator of the shift in product distribution to be anticipated. The effect of catalysts on rate and product distribution are discussed in the proceeding sections. 


\section{Gasification Rate}

The TGA reactor measures gasiffcation conversion "on-1ine" as a function of time and allows multiple runs per day. It was, therefore, the primary means of catalyst screening.

The gastfication parameters evaluated included:

- Catalyst type and method of application,

- Temperature,

- Wood type,

- Wood particle size, and

- Effect of pelletizing.

U1timate and particle size analyses of the wood used in these experiments are shown in Table 1. The analyses shown are for the samples after they have been dried and ground to the particle size range shown.

Wherever possible, the particle size of the wood samples for TGA evaluation has been selected to be plus 70 mesh, since the sample basket in TGA is made of 100 mesh screen. However, In many cases, the treated wood was pelletized in a lab scale pelletizer prior to TGA evaluation. To verffy that pelletization did not affect the reactivity evaluation, a series of experiments was conducted with unpelletized and pelletized wood samples. Also, in the same serles of experlments, various anple size and stean flow rates were used to insure heat and mass transfer were not the 11miting factors.

Comparison of Slurry Impregnated and Dry Mixed Catalyst Systems $-\mathrm{CaO}_{2} \mathrm{Na}_{2} \mathrm{CO}_{3} / \mathrm{CaO}$,

$$
\mathrm{Na}_{2} \mathrm{CO}_{3} \text { and } \mathrm{NaOH}
$$

Chemical incorporation of calcium fons into the wood structure from an aqueous slurry of wood and $\mathrm{CaD}$ was the infial goal of the expertmental work. As mentloned, this was due to our coal catalysis work (1) that demonstrated the superiority of CaO that is "chemically" incorporated from h1gh-temperature aqueous slurries compared to CaO that was simply physically mixed. 
TABIE 1. WOOD ANALYSES AND PARTICLE SIZE DISTRI8UTION

\begin{tabular}{|c|c|c|c|c|c|c|c|c|}
\hline \multirow[b]{2}{*}{ Wood Sample } & \multirow[b]{2}{*}{ 0ak } & \multirow[b]{2}{*}{$\operatorname{Mead}(a)$} & \multirow[b]{2}{*}{ Sweetgum } & \multirow[b]{2}{*}{ Sycamore } & \multicolumn{2}{|c|}{ Guaranty } & \multicolumn{2}{|c|}{ B1osolar } \\
\hline & & & & & Raw Wood & Pellets & Raw Wood & Pellets \\
\hline \multicolumn{9}{|c|}{ Analyges, wt percent } \\
\hline Molsture & 1.55 & 5.6 & 15.7 & 21.5 & 5.26 & 5.48 & 9.47 & 11.5 \\
\hline Ash & 1.51 & 0.59 & 1.77 & 0.78 & 1.66 & 1.35 & 1.48 & 1.57 \\
\hline Total Carbon & 50.0 & 45.8 & 42.0 & 39.5 & 47.6 & 47.2 & 49.3 & 48.3 \\
\hline Carbon (MAF) & 51.6 & 48.8 & 50.9 & 50.8 & & & & \\
\hline \multicolumn{9}{|c|}{$\begin{array}{l}\text { Particle Size Dlstribution, } \\
\text { wt percent en USS mesh size }\end{array}$} \\
\hline+12 & 0.1 & 0.15 & 0.14 & 0.12 & & & & \\
\hline$-12+30$ & 50.8 & 37.93 & 48.94 & 28.66 & & & & \\
\hline$-30+70$ & 41.1 & 44.67 & 36.45 & 52.82 & & & & \\
\hline-70 & 8.0 & 17.24 & 14.47 & 18.40 & & & & \\
\hline
\end{tabular}

(a) Obtained from the Mead Paper Company's pulp chip Inventortes In Cht111cothe, ohto. The wood contains about 90 percent Oak. 
With coal, the amount of CaO that can be chemically incorporated is increased by the addition of $\mathrm{NaOH}$ and $\mathrm{Na}_{2} \mathrm{CO}_{3}$ with the $\mathrm{CaO}$. Apparenty, the Na ions react with more sites than $\mathrm{Ca}$ ions alone and are then replaced by Ca lons via ion exchange. Treatment of coal with the mixed catalyst system produces an extremely reactive material and therefore some exploratory tests were run applying this technique to wood.

In the treatment of wood with the above catalysts in an aqueous slurry, the primary treatment parameters are treatment temperature and the catalyst/wood weight ratio. (The pressure of the system is maintained high enough to maintain an aqueous phase at the desired temperature.)

Table 2 is a summary of treatment conditions used to catalyze the wood. One of the problems encountered with elevated temperature slurry treatment of wood is wood loss through solubility. Thus, Table 2 also contalns the percent of wood solids that were recovered after treatment. Attempts at recovering the dissolved solids by drying the filtrate were only partlally successful. Apparently, a portion of the dissolved species volatize upon drying. As the data in Table 2 indicate, the solubility increases wth Increasing temperature and decreasing $\mathrm{pH}$. Thus, to reduce solubility at the elevated temperature it is necessary to increase the CaO/wood ratio.

In an integrated plant, the volatile species that are solubilized during treatment would probably end up in the water used to scrub the gasiffer effluent of particulate matter and would thereby represent a loss of energy to the process and result in increased water treatment requirements in the plant.

Gasification tests were conducted on most of the samples produced at the conditions listed in Table 2. Complete results of these tests are included in an Appendix Report covering all the experimental work done during the first phase of this program.

The relattve effectiveness of CaO slurry treatment compared to simply dry mixing the same anount of $\mathrm{CaO}$ with wood was evaluated by gasifying wood samples prepared both ways. Total conversion as a function of time for untreated wood is compared with $\mathrm{CaO}$ treated wood where the $\mathrm{CaO}$ is applied from a $210 \mathrm{C}$ slurry and by dry wixing in Figure 3 indicate that 
TABLE 2. SUMMARY OF WOOD SOLUBILITY DURING SLURRY TREATMENT

\begin{tabular}{|c|c|c|c|c|c|c|}
\hline $\begin{array}{l}\text { Treatment } \\
\text { Number }\end{array}$ & $\begin{array}{l}\text { Hood } \\
\text { Type }\end{array}$ & $\begin{array}{l}\text { Particle } \\
\text { Size }\end{array}$ & $\begin{array}{l}\text { Catalyst } \\
\text { Hood }\end{array}$ & Tenp., & $\begin{array}{c}\mathrm{pH} \text { of } \\
\text { F1ltrate }\end{array}$ & $\begin{array}{l}\text { Wood Sol1ds Y1eld } \\
\text { Undissolved } \\
\text { (Corrected \% of Input) }\end{array}$ \\
\hline \multicolumn{7}{|l|}{ Wood Type } \\
\hline 2 & Oak & $30 \times 70$ & $\mathrm{CaO} \quad 0.05$ & 210 & 4.3 & - \\
\hline 24 & Sweetgum & & & & 4.6 & 93.6 \\
\hline 25 & Sycamore & & & & 4.45 & 80.3 \\
\hline 26 & Mead & & & & 4.4 & 82.2 \\
\hline \multicolumn{7}{|c|}{ Particle Size } \\
\hline 29 & Oak & $12 \times 30$ & $\mathrm{CaO} 0.05$ & 211 & 4.35 & 75.8 \\
\hline 28 & & $30 \times 70$ & & 212 & 4.45 & 74.6 \\
\hline 30 & & -70 & & 211 & 4.6 & 80.4 \\
\hline \multicolumn{7}{|c|}{ Temperature } \\
\hline 13 & Oak & $30 \times 70$ & $\mathrm{CaO} 0.10$ & 120 & 11.6 & 93.7 \\
\hline 12 & & & & 150 & 11.6 & 94.9 \\
\hline 7 & & & & 180 & 11.3 & 92.7 \\
\hline 23 & & & & 210 & 5.9 & 89.6 \\
\hline 18 & & & & 238 & 4.5 & 77.4 \\
\hline 11 & Dak & $30 \times 70$ & $\mathrm{CaO} \quad 0.3$ & R.T. & 12.1 & 98.1 \\
\hline 9 & & & & 180 & 11.6 & 95.0 \\
\hline 10 & & & & 210 & 11.5 & 91.3 \\
\hline 19 & & & & 240 & 11.3 & 87.4 \\
\hline \multicolumn{7}{|c|}{ Catalyst/Hood Rat10 } \\
\hline 8 & Oak & $30 \times 70$ & $\mathrm{CaO} 0.0$ & 210 & 3.4 & 75.9 \\
\hline 2 & & & 0.05 & & 4.3 & - \\
\hline 23 & & & 0.1 & & 5.9 & 89.6 \\
\hline 10 & & & 0.3 & & 11.5 & 91.3 \\
\hline \multicolumn{7}{|l|}{ Catalyst } \\
\hline 6 & Oak & $30 \times 70$ & $\mathrm{CaO} 0.05$ & 205 & 4.5 & 68.4 \\
\hline 22 & & & $\mathrm{Na}_{2} \mathrm{CO}_{3} \quad 0.05$ & 200 & 4.4 & 81.6 \\
\hline 21 & & & $\begin{array}{c}\mathrm{Ha}_{2} \mathrm{CO}_{3} 0.05 / \\
\mathrm{CaO} 0.05\end{array}$ & 200 & 5.5 & 87.8 \\
\hline 14 & Oak & $30 \times 70$ & None & 180 & 3.6 & 81.2 \\
\hline $4(\mathrm{~b})$ & & & $\mathrm{CaO} 0.05$ & 195 & 4.6 & - \\
\hline 15 & & & $\mathrm{Na}_{2} \mathrm{CO}_{3} 0.05$ & 180 & 4.9 & 92.3 \\
\hline 16 & & & $\mathrm{NaOH} 0.05$ & 180 & 5.2 & 93.9 \\
\hline 17 & & & $\begin{array}{c}\mathrm{Na}_{2} \mathrm{CO}_{3} 0.05 / \\
\mathrm{CaO} 0.05\end{array}$ & 180 & 6.1 & 94.3 \\
\hline
\end{tabular}




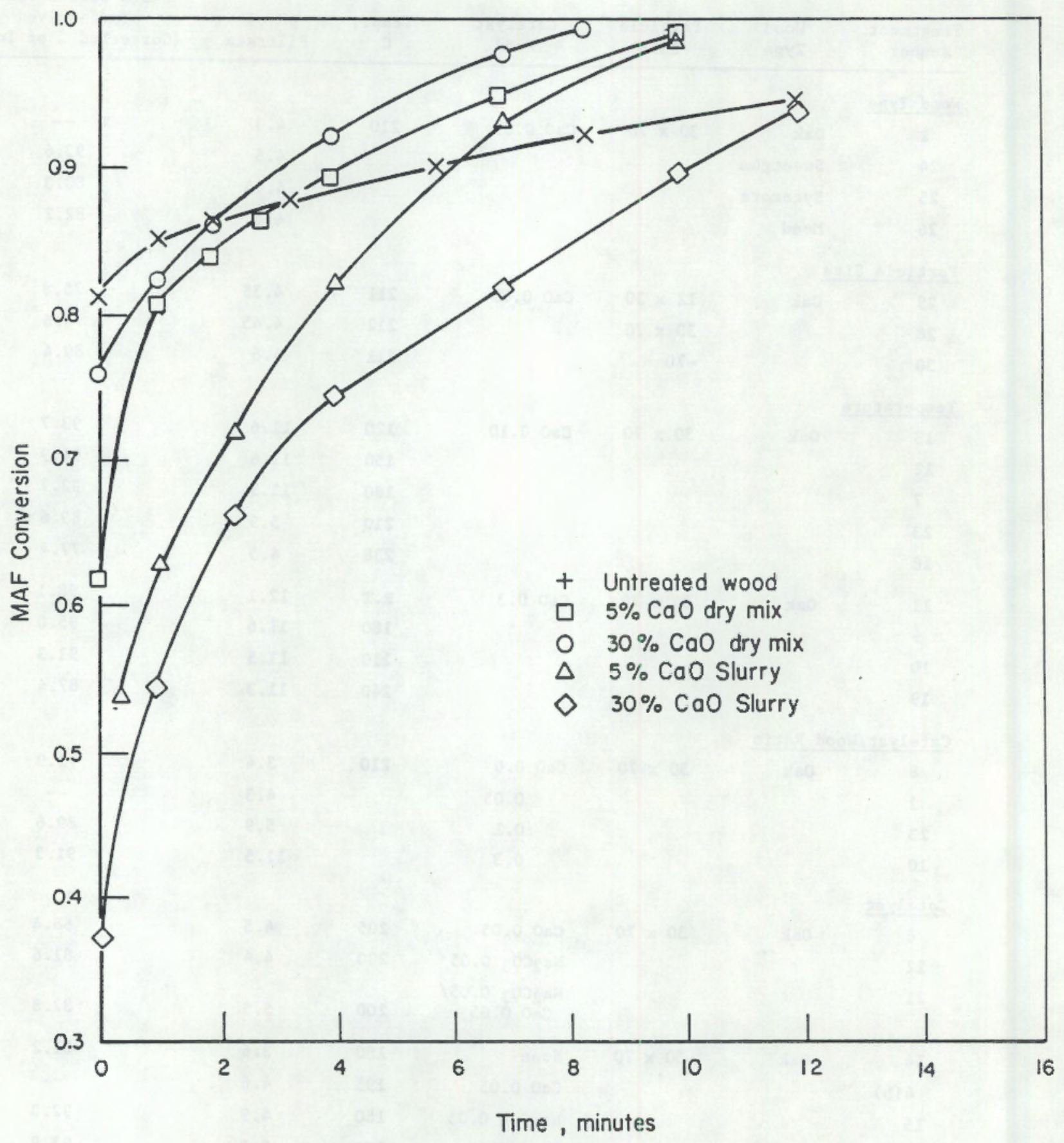

FIGURE 3. EFFECT OF CaO CONCENTRATION ON GASIFICATION REACTIVITY AT $750^{\circ} \mathrm{C}$ 
simply dry mixing the CaO with the wood is as effective as the slurry treatment and increasing the $\mathrm{CaO}$ concentration above $0.05 \mathrm{lb} / 1 \mathrm{~b}$ wood does not result in further increases in reactivity. Thus, these data suggest that lower $\mathrm{CaO} /$ wood ratios may be effective.

Another interesting result of this comparison is that slurry treatment apparently reduced the fraction of wood that "instantaneously" gasifies. One reasonable explanation is that the wood that is solubilized during treatment and then volatized and "lost" during drying is the most reactive fraction of the wood. Another explanation is that not only solubilization occurs but that the remaining wood undergoes some polymerization which reduces its rate of thermal decomposition. However, as will be discussed later, the initial high rate of gasification was reduced over that of raw wood even when catalyst was incorporated at conditions where no volatile loss would be anticipated.

In spite of a slower devolatilization rate, treatment by $\mathrm{CaO}$ whether by dry mixing or high-temperature slurry does allow a relatively high gasification rate to be attained until almost complete conversion is achieved in contrast to the untreated wood which loses a larger fraction of 1 ts weight Immediately but then gasifies at a greatly reduced rate. Because total conversion levels of over 90 percent are required to avold the production of byproduct char, catalysis with $\mathrm{CaO}$ can significantly reduce the residence time required.

Based on these results, dry treatment with $\mathrm{CaO}$ would be much better than slurry treatment.

It should be noted that the rate measurements made with $\mathrm{CaO}$ had to be corrected for carbonate formation. This correction is due to the reaction $\mathrm{CaO}+\mathrm{CO}_{2} \rightleftarrows \mathrm{CaCO}_{3}$ which increases the sample weight thereby reducing the apparent measured gasification rate. The correction depends of course on the $\mathrm{CaO}$ content of the treated wood. At 5 to 10 weight percent, the correction is not critical however at higher levels of $\mathrm{CaO}$ the correction must be made to accurately Interpret the data.

In an attempt to increase the effectiveness of CaO treatment and also to compare $\mathrm{CaO}$ with $\mathrm{Na}_{2} \mathrm{CO}_{3}$ which is generally accepted as an excellent gasification catalyst for cellulosic materlals wood was slurry treated with 
$\mathrm{Na}_{2} \mathrm{CO}_{3} / \mathrm{CaO}$ and $\mathrm{Na}_{2} \mathrm{CO}_{3}$ alone. Results of these experiments are summarized in Figure 4. These data indicate that $\mathrm{CaO}$ by itself is a more effective catalyst than $\mathrm{Na}_{2} \mathrm{CO}_{3}$ and that there is no incentive for using the mixed $\mathrm{CaO} / \mathrm{Na}_{2} \mathrm{CO}_{3}$ system (shown in our work on coal to be more effective than $\mathrm{CaO}$ alone).

These results also show the negative effect of treatment temperature on gasification rate when the conversion curves for $\mathrm{Na}_{2} \mathrm{CO}_{3}$ alone and $\mathrm{CaO} / \mathrm{Na}_{2} \mathrm{CO}_{3}$ are compared at 170 and $200 \mathrm{C}$ treatment temperatures. Again, the treated samples while having a reduced initial activity maintain this reactivity until completely converted while the reactivity of the untreated wood is greatly reduced once the more volatile constituents are converted.

\section{Soluble Catalysts - Calcium Acetate and Nitrate, Potassium, and Sodium Carbonates}

Experiments were also made using soluble calcium compounds to determine if the solubility would increase the effectiveness of catalyst impregnation and thereby enhance reactivity. Both calcium acetate and nitrate were used in these experiments. In a few experiments, the filter cake was autoclaved to determine the effect of elevated temperature on reactivity. The reason for autoclaving the filter cake was to determine if incorporating the catalytic agent throughout the wood before heating to encourage chemical reaction between wood and catalyst was effective.

The soluble calcium compounds listed above were also compared with the more conventional $\mathrm{Na}_{2} \mathrm{CO}_{3}$ and $\mathrm{K}_{2} \mathrm{CO}_{3}$ catalysts applied from solution.

Steam gasification results using these catalysts are summarized In Figure 5 which illustrates that they all increase the reactivity of wood with the $\mathrm{K}_{2} \mathrm{CO}_{3}$ being by far the best catalyst while $\mathrm{Na}_{2} \mathrm{CO}_{3}$ and $\mathrm{Ca}(\mathrm{OAc}) 2$ are about equivalent.

Some experiments were also made with $\mathrm{K}_{2} \mathrm{CO}_{3}$ to determine the effect of the $\mathrm{K} /$ wood ratio. The results of these experiments are summarized in Figure 6 which shows that little 1mprovement is brought about by increasing the $\mathrm{K} /$ wood ratio above $.03 \mathrm{lbs} \mathrm{K} / \mathrm{lb}$ wood. 


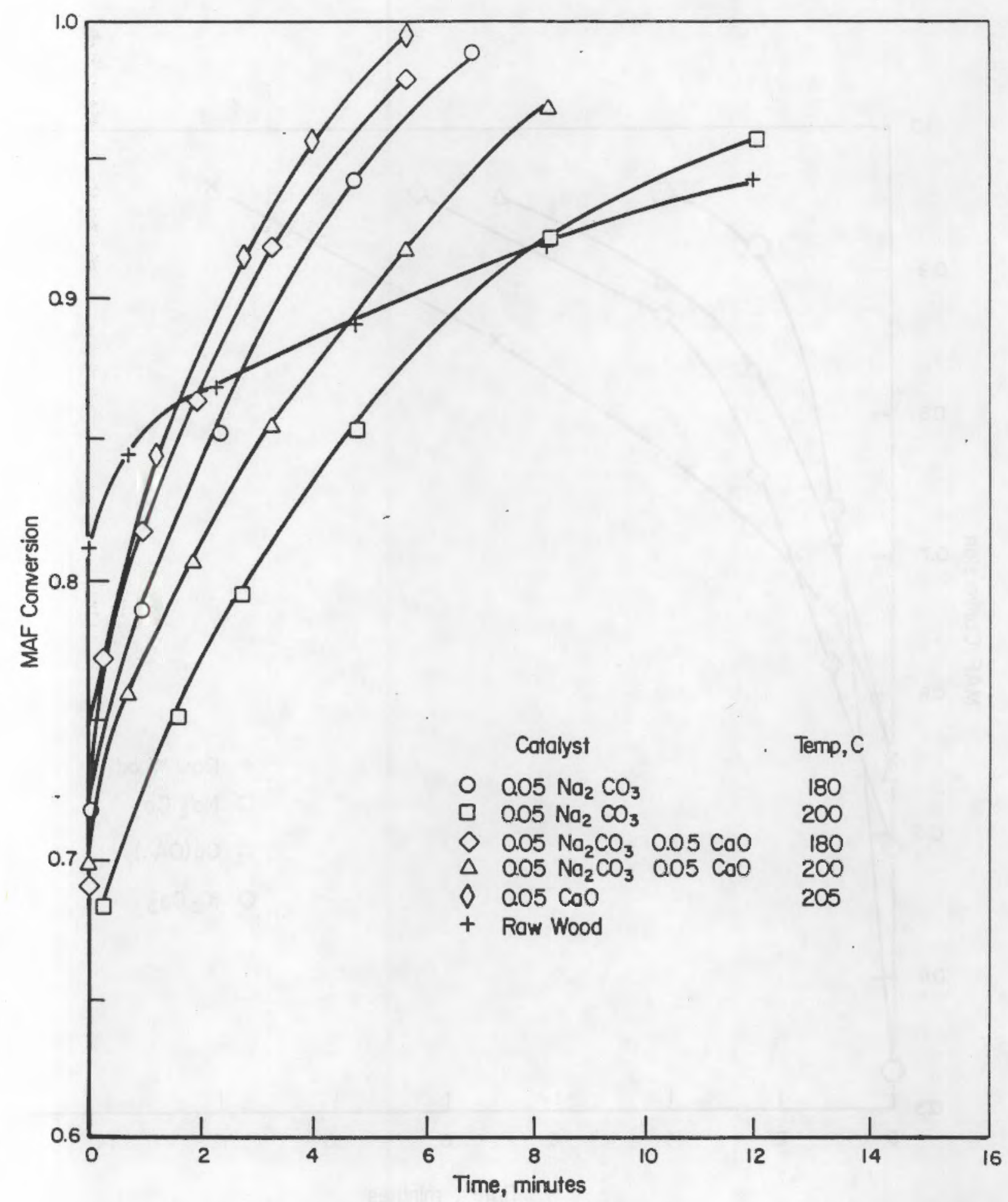

FIGURE 4. COMPARISON OF CATALYSES WITH $\mathrm{Na}_{2} \mathrm{CO}_{3}$ WITH $\mathrm{CaO}, \mathrm{Na}_{2} \mathrm{CO}_{3}-\mathrm{CaO}$ AND RAW WOOD, CATALYST?WOOD RATIO $=0.05$. STEAM GASIFICATION AT $750^{\circ} \mathrm{C}$ 


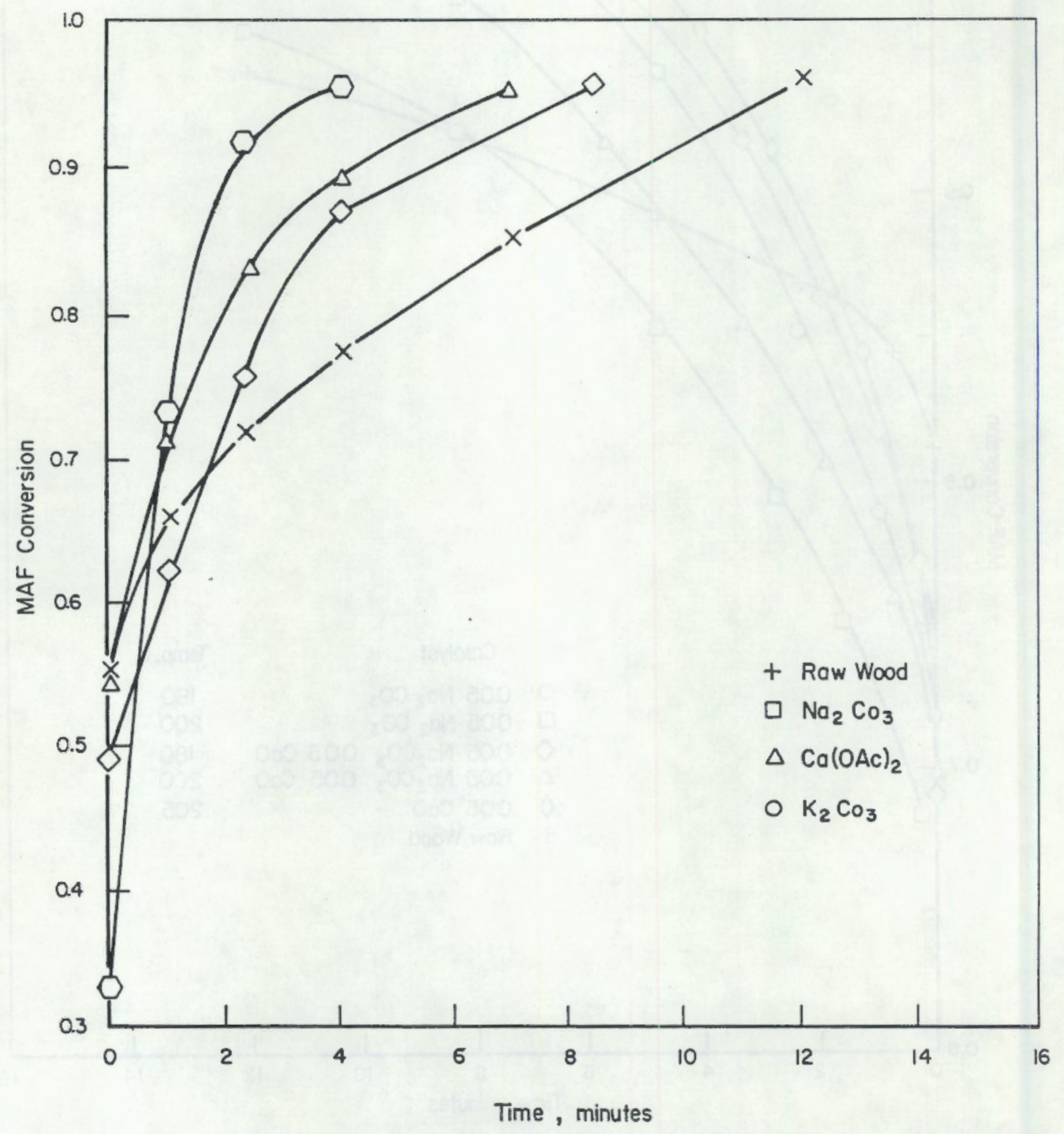

FIGURE 5. STEAM GASIFICATION OF SWEETGUM AT $750^{\circ} \mathrm{C}$. COMPARISON OF CATALYSTS FROM SLURRY TREATMENT 


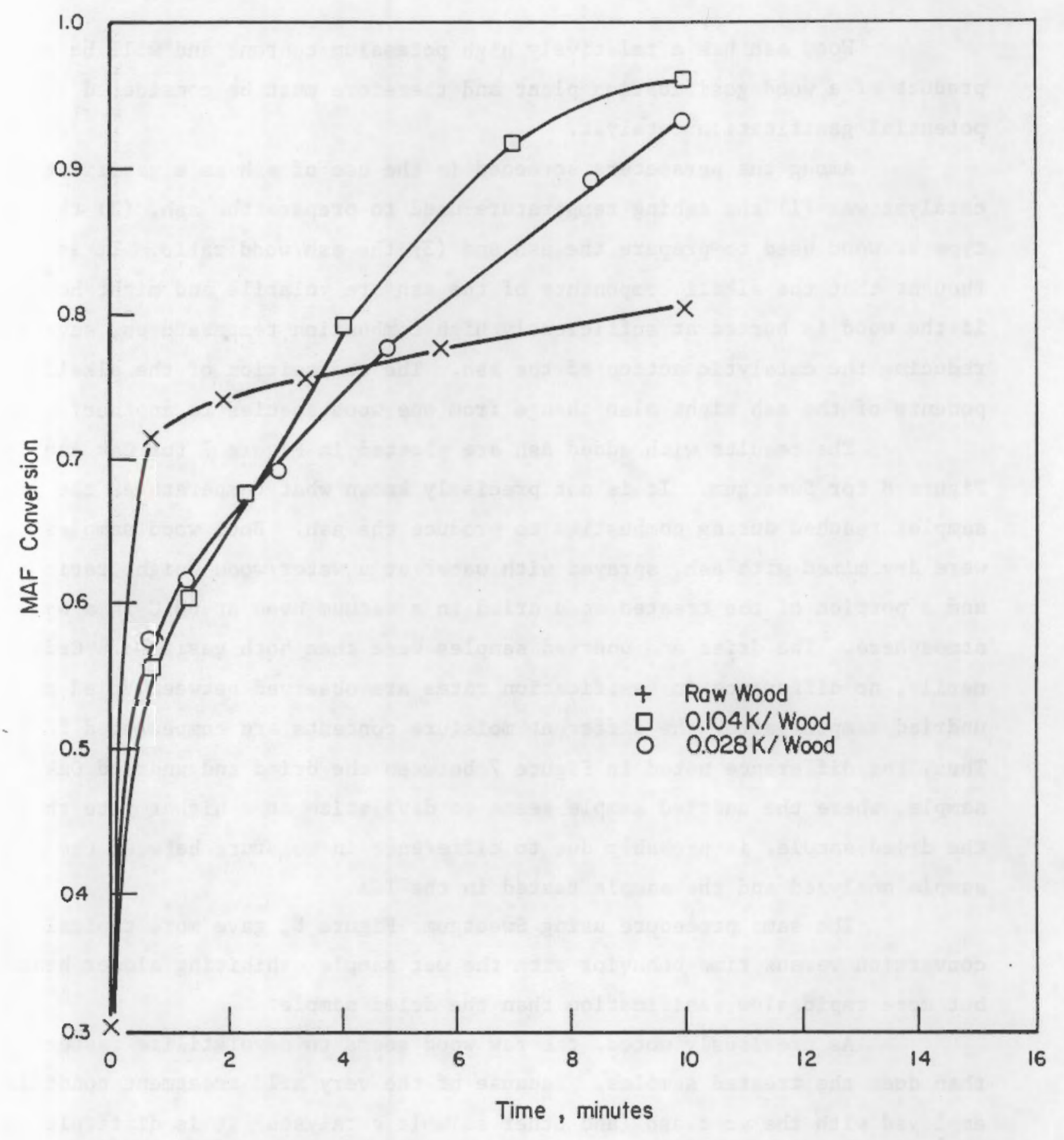

FIGURE 6. EFFECT OF $\mathrm{K}_{2} \mathrm{CO}_{3}$ /WOOD RATIO. STEAM GASIFICATION OF SWEETGUM AT $650^{\circ} \mathrm{C}$ 
Wood Ash

Wood ash has a relatively high potassium content and will be a byproduct of a wood gasification plant and therefore must be considered as a potential gasiflcation catalyst.

Among the parameters screened in the use of ash as a gasification catalyst was (1) the ashing temperature used to prepare the ash, (2) the type of wood used to prepare the ash and (3) the ash/wood ratio. It is thought that the alkali components of the ash are volatile and might be lost if the wood is burned at sufficiently high combustion temperatures, severely reducing the catalytic action of the ash. The composition of the alkali components of the ash might also change from one wood species to another.

The results with added ash are plotted in Figure 7 for Oak and in Figure 8 for Sweetgum. It is not precisely known what temperatures the samples reached during combustion to produce the ash. Both wood samples were dry mixed with ash, sprayed with water at a water/wood weight ratio = 1 and a portion of the treated wood dried in a vacuum oven at $60 \mathrm{C}$ in a $\mathrm{N}_{2}$ atmosphere. The dried and undried samples were then both gasified. Ordinar1ly, no difference in gasification rates are observed between dried and undried samples after the different moisture contents are compensated for. Thus, the difference noted in Figure 7 between the dried and undried Oak sample, where the undried sample seems to devolatize at a higher rate than the dried sample, is probably due to difference in moisture between the sample analyzed and the sample tested in the TGA.

The same procedure using Sweetgum, Figure 8, gave more typical conversion versus time behavior with the wet sample exhibiting slower heatup but more rapid slow gasification than the dried sample.

As previously noted, the raw wood seems to devolatilize faster than does the treated samples. Because of the very mild treatment conditions employed with the wood ash (and other soluble catalysts) it is difficult to Imagine that volatile matter is lost during treatment. However, from a reactor design viewpolnt, the critical question is how much residence time 


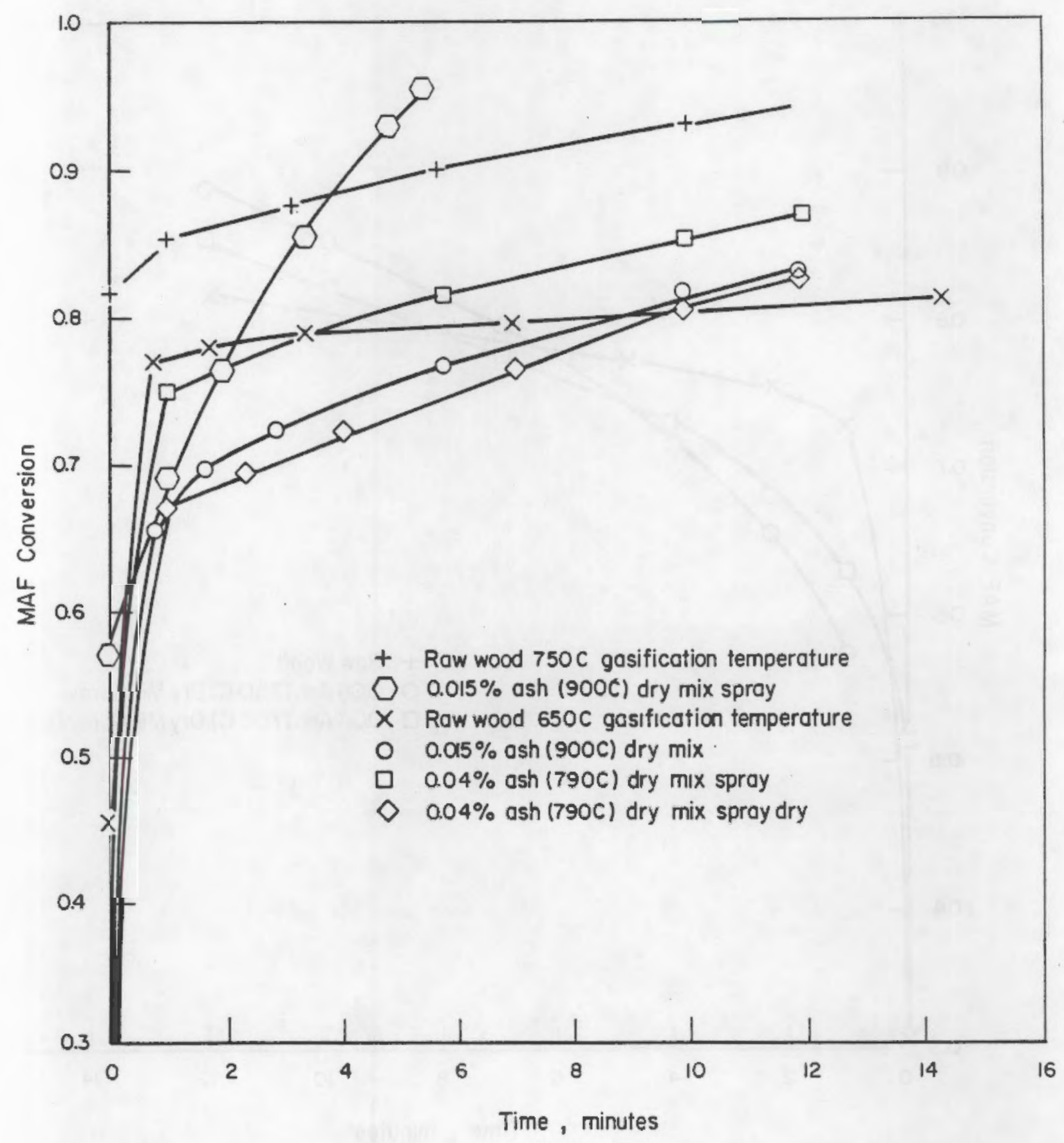

FIGURE 7. CATALYSIS WITH RECYCLE ASH. STEAM GASIFICATION OF OAK 


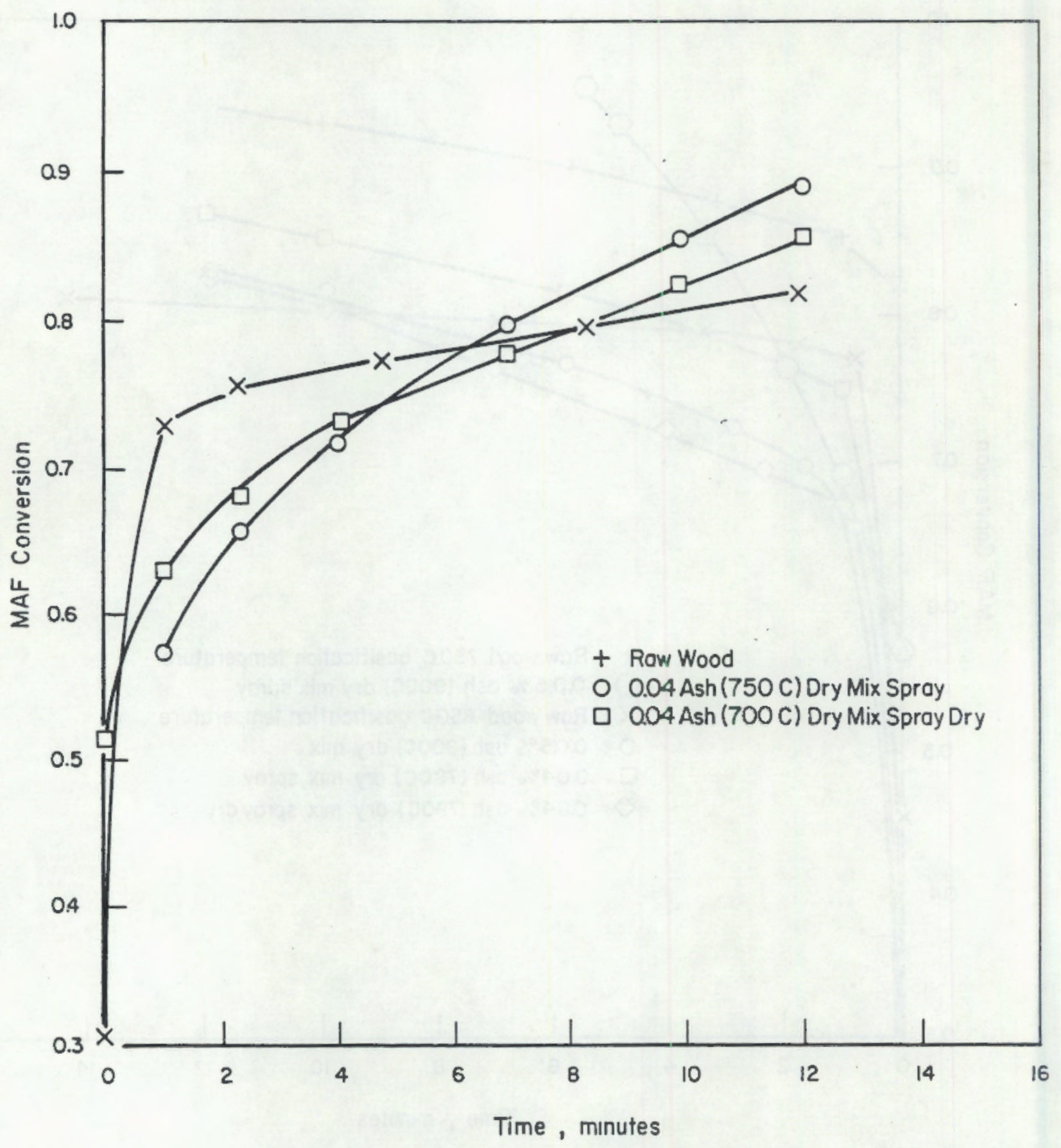

FIGURE 8. CATALYSIS WITH RECYCLE ASH. STEAM GASIFICATION OF SWEETGUM AT $650^{\circ} \mathrm{C}$ 
is required to achieve the 90 to 95 percent MAF (moisture and ash-free) conversion required and the rate curves indicate that treatment with wood ash greatly reduces the overall residence time required in spite of a reduced initial rate.

Mechanism of Catalytic Action

The objective of this work was not to study the mechanism of catalytic action. Nevertheless, it is interesting to speculace on how the alkali catalysts influence gaslfication reactivity. Figure 9 shows the conversion/reaction time curve that is typical of the catalysts studied.

As Figure 9 shows, gasification of uncatalyzed wood is characterized by a very high rate of devolatilization that produces a char that is relatively unreactive while the effect of catalysis is to eliminate the tendency of the wood to deactivate. A plausible chemical explanation is that the alkali species act as a polymerization retardant. It is reasonable to expect that stabilization of the thermally ruptured bonds that result in the evolution of volatile species is accomplished by polymerization of the remaining solid radicals. Thus, in raw wood there is very rapid pyrolysis resulting in a relatively unreactive char and volatile products. On the other hand, addition of the alkali species retards polymerization and pyrolysis but in doing so maintains a chemical structure that can be more easily gasified.

In a commercial plant, it w11l be necessary to convert over 90 percent of the total wood in order to avold a char by-product. Therefore, the catalytic effect is important because it allows the achievement of such high conversion levels without the necessity of gasffying an unreactive residual char. 


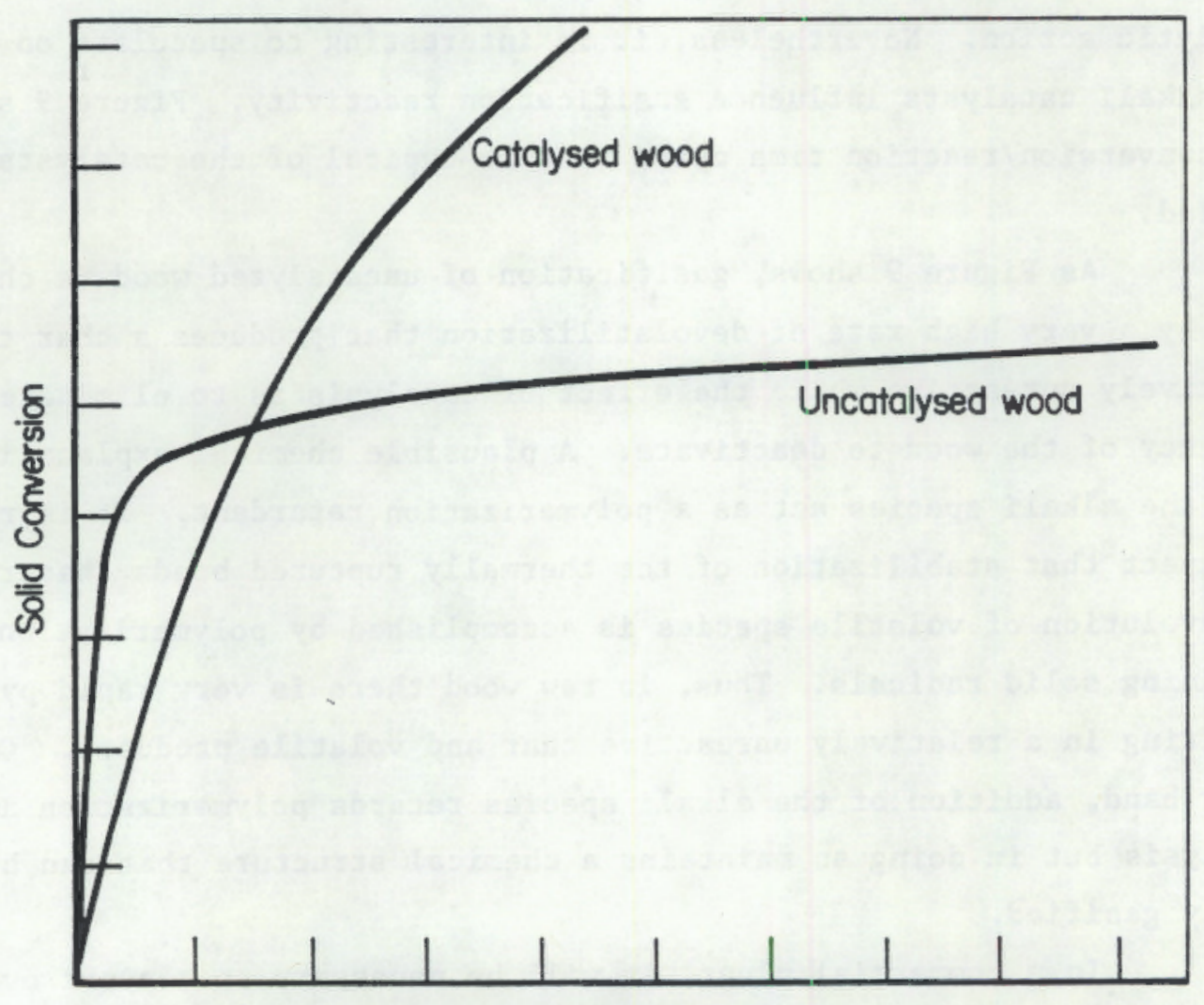

Reaction Time

FIGURE 9. GASIFICATION OF ALKALI CATALYZED AND UNCATALYZED WOOD 
Selection of the Most Promising Catalyst System

Based on Reactivity Enhancement

As already indicated, wood ash because of its effectiveness and availability as a byproduct of a wood gasification plant appears the best catalyst for further study. However, $\mathrm{CaO}$ may also have merit because of its low cost and effectiveness in low concentration. While $\mathrm{K}_{2} \mathrm{CO}_{3}$ has the greatest effect on gasification rate its high cost make its recovery and recycle essential and therefore it appears less attractive. For example, the reduction in gasffication residence time brought about by $\mathrm{K}_{2} \mathrm{CO}_{3}$ compared to wood ash and $\mathrm{CaO}$ will probably not allow a cost reduction sufficient to pay for the additional untt operations needed for its reocvery and recycle.

The performance of these catalytic agents in promoting reactivity is shown in Figure 10. The basis for performance in these catalytic screening studies is the time required to achieve a 95 percent total conversion level at $750 \mathrm{C}$. As the figure Indicates, the best catalyst from a performance point of view is $\mathrm{K}_{2} \mathrm{CO}_{3}$ which reduces the time required to achieve the desired conversion by a factor of about 4 .

Wood ash reduces the conversion time by a factor of over 2 and can be effectively applied by spraying $1 \mathrm{t}$ on the ch1ps. In an integrated plant, wood ash w1ll be a byproduct and therefore available at only the cost of its application. Further, the amount required is very modest being only 1.5 percent of the weight of the wood.

\section{Effect of Wood Type and Properties on Gasification Rate}

In addition to the catalyst and method of application experiments discussed above, the effect of wood physical properties and temperature on gasification rate were also studied. These experiments were made to insure that the catalyst screening studies were done at appropriate conditions and also to determine whether wood pelletizing would have a deleterious effect on reactivity. Pelletizing is of interest because it is one way of converting sawdust and chips for example, to a suitable feed for a fixed-bed gasifler. 


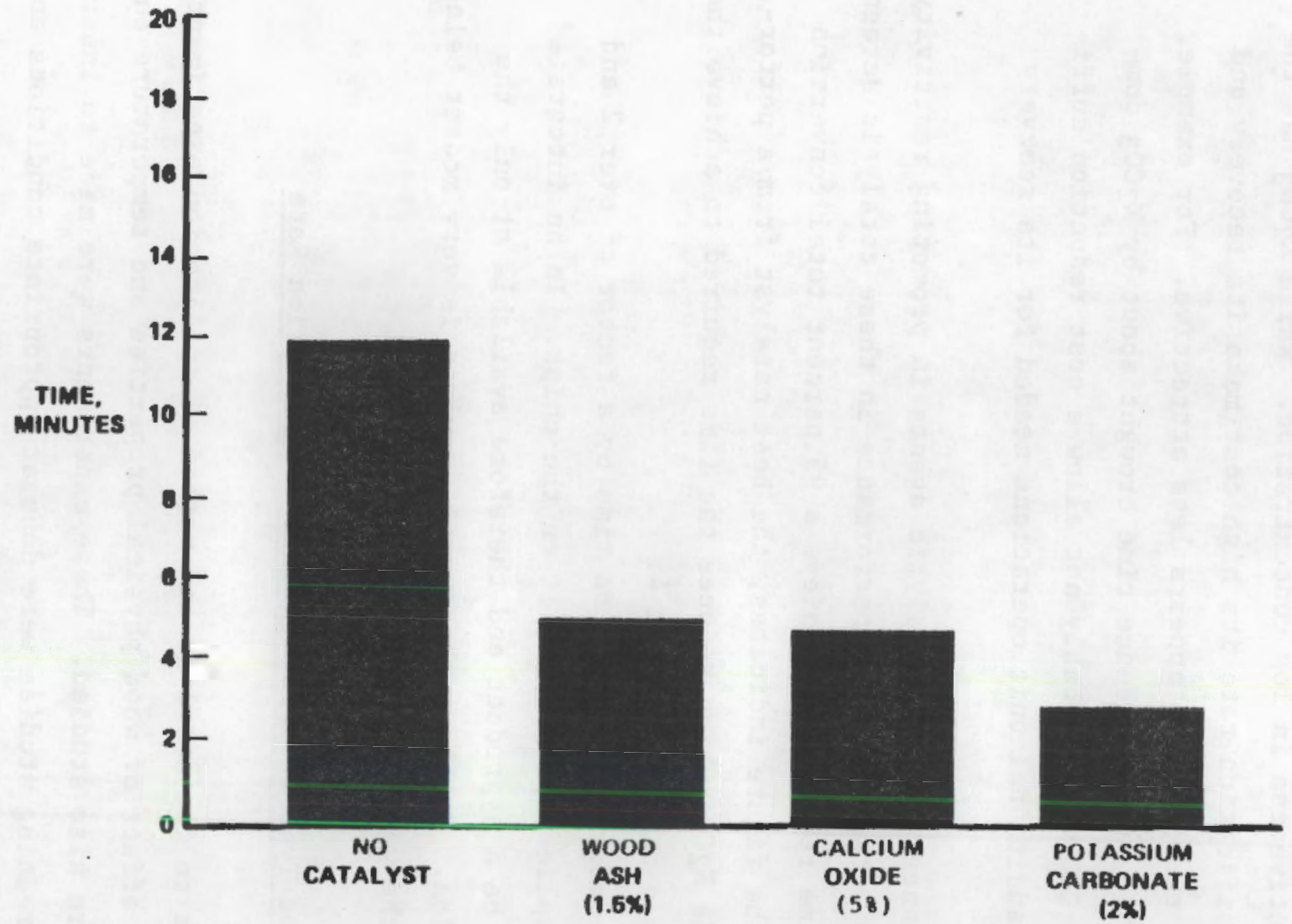

FIGURE 10. TIME REQUIRED TO CONVERT 95 PERCENT OF THE WOOD AT $750 \mathrm{C}$ 
Summarized below are the results describing the effects of the following parameters on gasification reactivity.

- Wood type

- Wood particle Size

- Temperature

- Pelletizlng.

Wood Type

Wood types studied included Oak, Sweetgum, Sycamore and a mixed sample obtained from the Mead Paper Company denoted as Mead I which is mostly hardwoods. Figure 11 shows that the Oak and Mead I samples lose more weight during the "Instantaneous" devolatilization period but all samples require about the same residence time to reach the target 95 percent total conversion level.

All these woods were then treated with $\mathrm{CaO}$ from a slurry at elevated temperature $(210 \mathrm{C})$ and pressure (1000 psig) after which they were gasified at $750 \mathrm{C}$. The conversion curves generated during gasification are shown in Figure 12. The reactivity difference noted between various types of raw woods was eliminated by treatment. The treatment employed, as later experiments demonstrated, was not the best and the conversion curves shown in Figure 12 were not corrected for $\mathrm{CO}_{2}$ capture (by analyzing for carbonate after the experiment). However, these experiments provided the basis for just1fying that further catalyt1c experiments could be conducted with a single wood type. As a consequence, Oak was used in most of the autoclave treatment experiments and Sycamore in the solution and dry mix catalyst experiments.

Wood Particle Size

Treatment and reactivity tests using Oak samples of three particle size fractions, $12 \times 30$ mesh, $30 \times 70$ and -70 mesh, USS sleve, indicate that there is no appreclable difference within this narrow particle size range. 


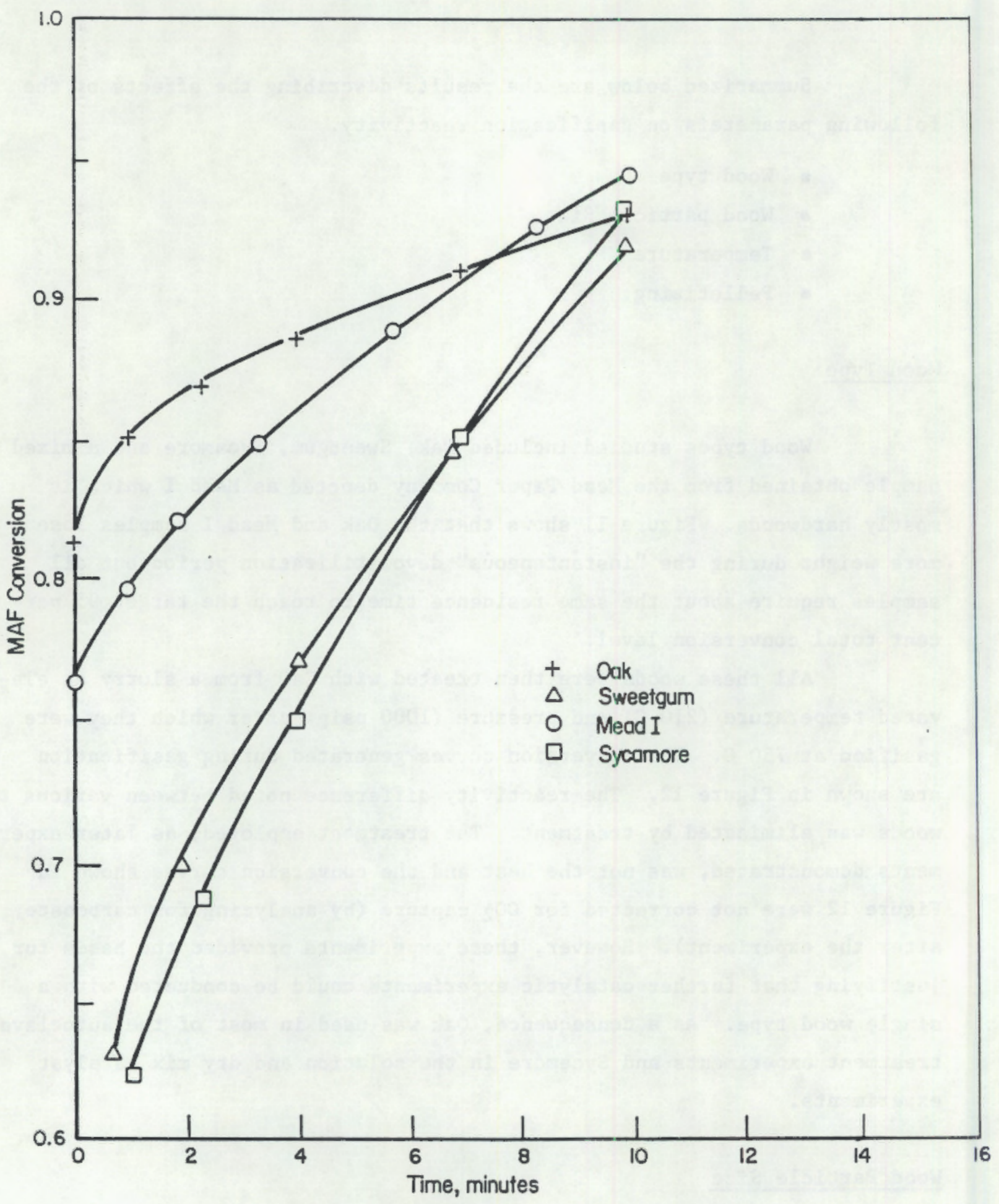

FIGUIRE 11. COMPARISON OF RAW WOOD STEAM GASIFICATION CONVERSIONS (MAF) VERSUS TIME AT $750^{\circ} \mathrm{C}$ 


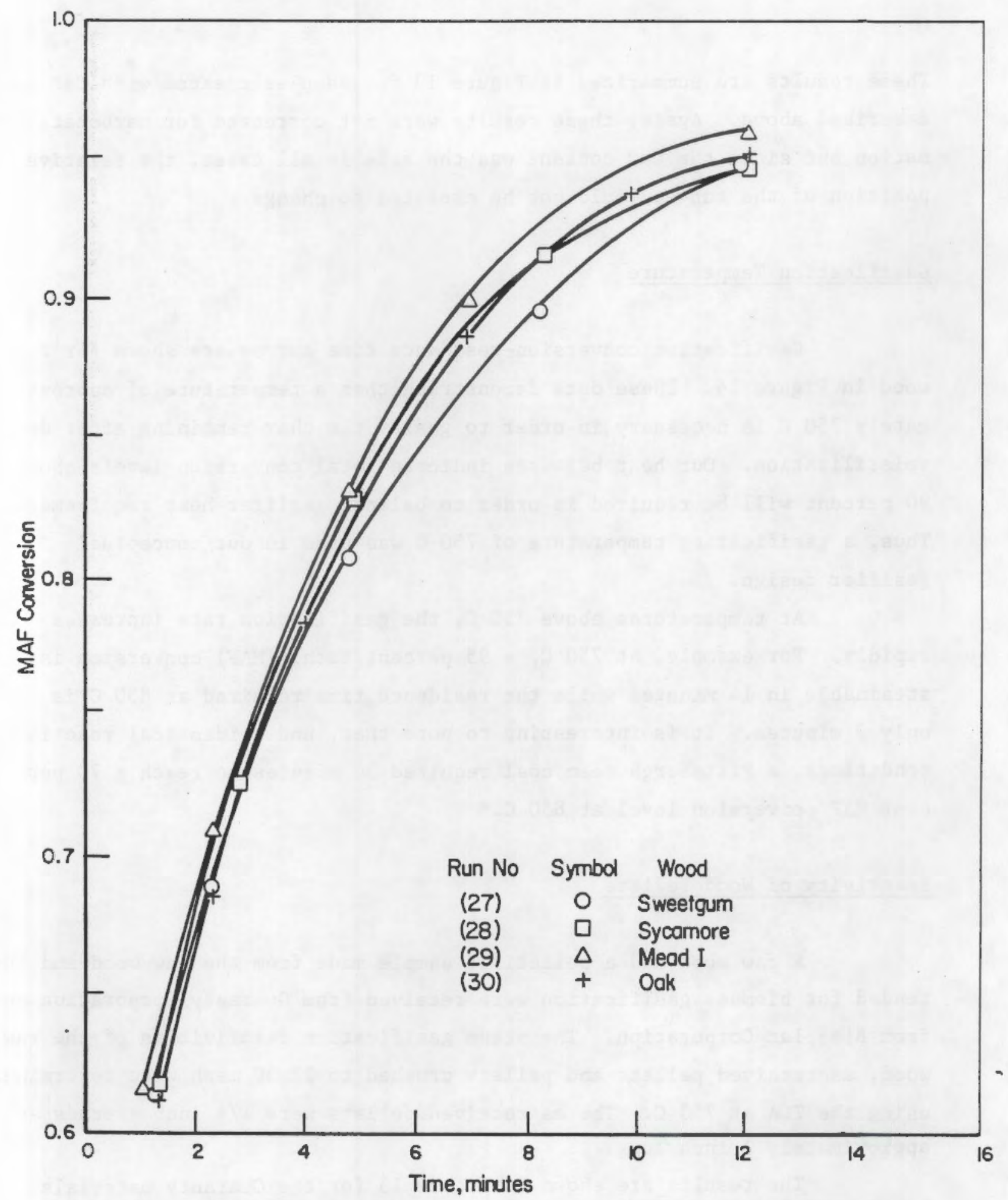

FIGURE 12. COMPARISON OF WOODS TREATED AT $210^{\circ} \mathrm{C}, 0.1 \mathrm{CaO} /$ WOOD FOR 1 HOUR. WATER/WOOD 6 , GASIFICATION AT $750^{\circ} \mathrm{C}$ 
These results are summarized in Figure 13 for samples treated with $\mathrm{CaO}$ as described above. Again, these results were not corrected for carbonate formation but since the $\mathrm{CaO}$ content was the same in all cases, the relative position of the curves would not be expected to change.

\section{Gasification Temperature}

Gasification conversion-residence time curves are shown for raw wood in Figure 14. These data demonstrate that a temperature of approximately $750 \mathrm{C}$ is necessary in order to gasify the char remaining after devolatilization. Our heat balances indicate total conversion levels above 90 percent w1ll be required in order to balance gasifier heat requirements. Thus, a gasification temperature of $750 \mathrm{C}$ was used in our conceptual gasifier design.

At temperatures above $750 \mathrm{C}$, the gasification rate increases rapidly. For example, at $750 \mathrm{C}$, a 95 percent total (MAF) conversion is attainable in 14 minutes while the residence time required at $850 \mathrm{C}$ is only 3 minutes. It is interesting to note that, under identical reaction conditions, a Pittsburgh seam coal required 30 minutes to reach a 70 percent MAF conversion level at $850 \mathrm{C}$. *

\section{Reactivity of Wood Pellets}

A raw wood and a pelletized sample made from the raw wood and intended for biomass gasification were received from Guaranty Corporation and from Biosolar Corporation. The steam gasification reactivities of the raw wood, as recelved pellets and pellets crushed to $12 \times 30$ mesh were determined using the TGA at $750 \mathrm{C}$. The as received pellets were $1 / 4$ inch extrudates approximately 1 inch long.

The results are shown in Figure 15 for the Guaranty materials. The raw wood in this case has a lower initial conversion rate than the

^DOE Summary Report, "A Novel Approach to Coal Gasificat1on Using Chemically Incorporated $\mathrm{CaO}$ (Phase II), Letter Contract No. W-7405-eng-92 (Task 79) (November 11, 1977). 


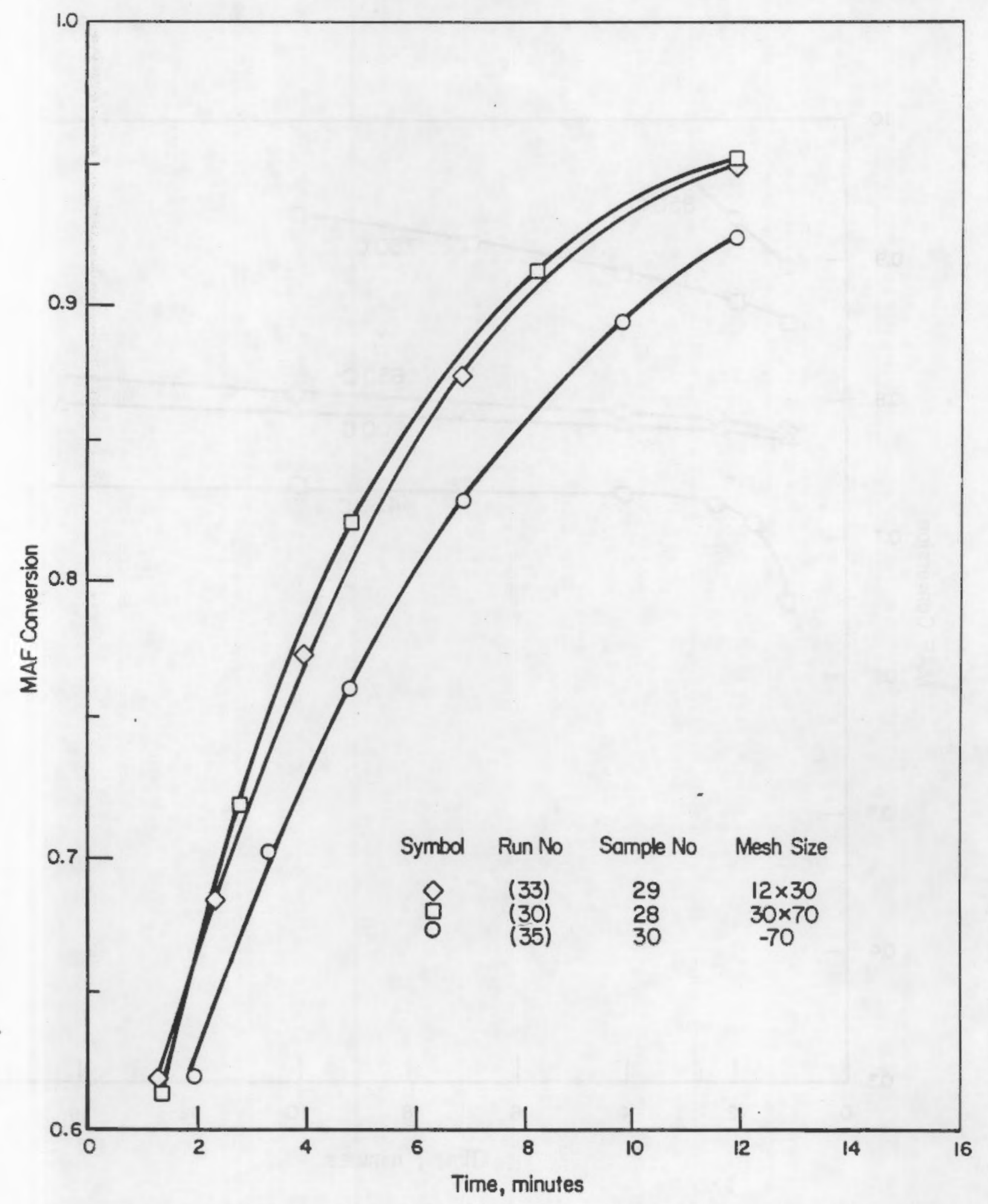

FIGURE 13. EFFECT OF WOOD PARTICLE SIZE. CaO/COAL $=0.05,210^{\circ} \mathrm{C}$ TREATMENT, WATER/CAOL $=6.0$ 


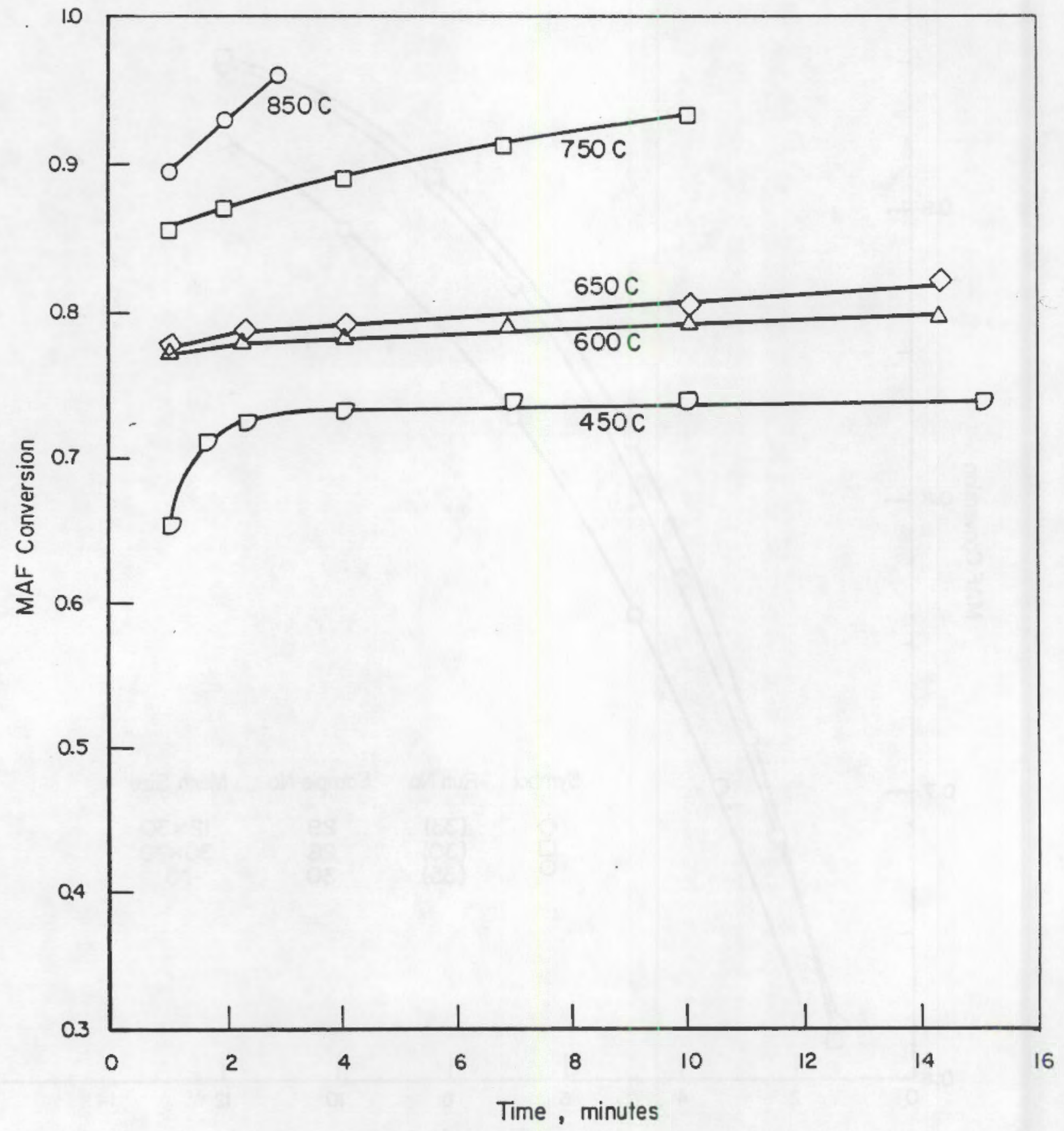

FIGURE 14. STEAM GASIFICATION OF RAW OAK VERSUS TEMPERATURE 


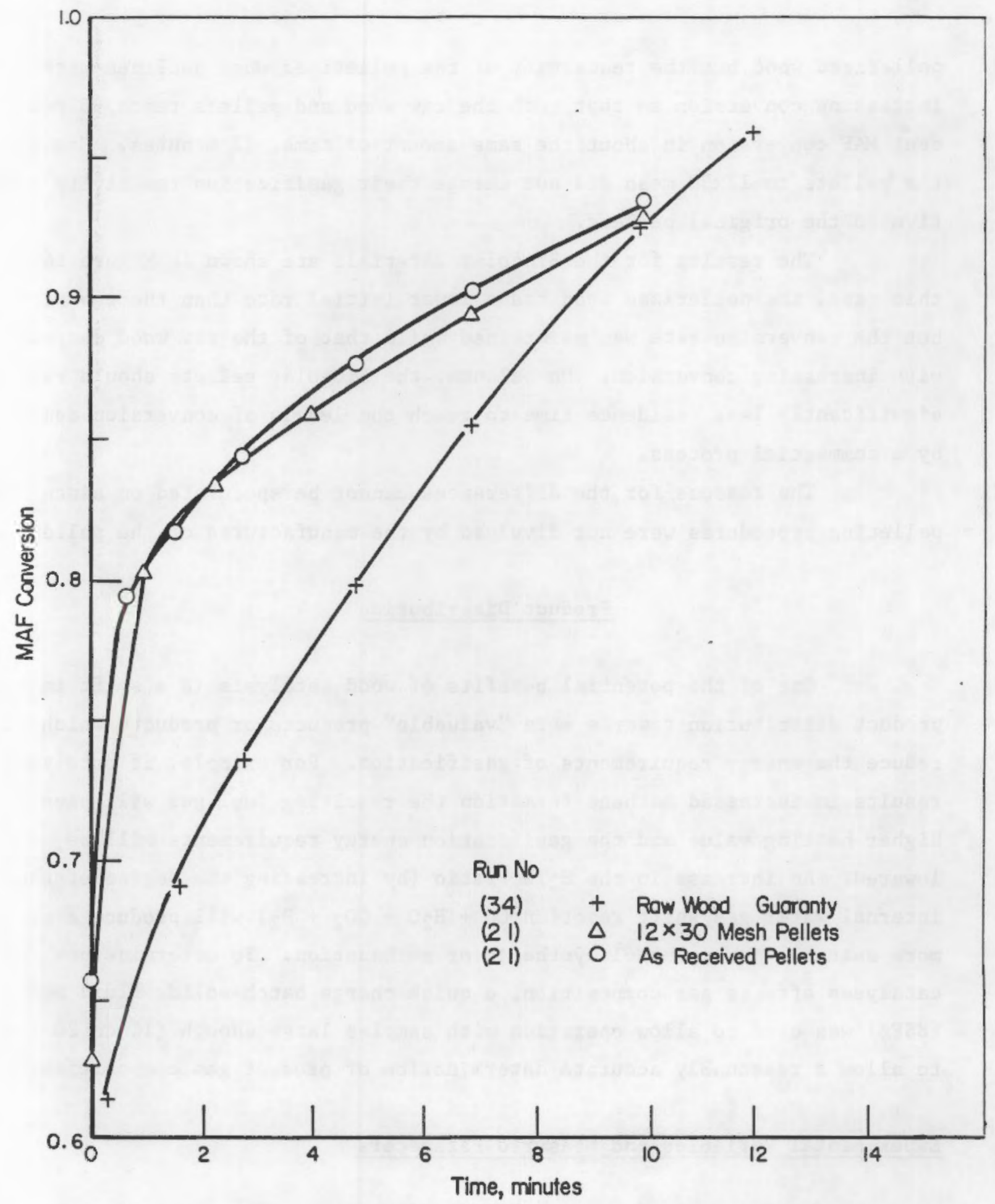

FIGURE 15. RESULTS OF STEAM GASIFICATION AT $750^{\circ} \mathrm{C}$. PELLETS AS RECEIVED AND CRUSHED TO $12 \times 30$ AND RAW WOOD FROM GUARANTY 
pelletized wood but the reactivity of the pelletized wood declines with increasing conversion so that both the raw wood and pellets reach 95 percent MAF conversion in about the same amount of time, 12 minutes. Crushing the pellets to $12 \times 30$ mesh did not change their gasification reactivity relative to the original pellets.

The results for the Biosolar materials are shown in Figure 16 . In this case, the pelletized wood had a lower initial rate than the raw wood but the conversion rate was maintained while that of the raw wood decreased with increasing conversion. On balance, the Biosolar pellets should require significantly less residence time to reach the levels of conversion demanded by a commercial process.

The reasons for the differences cannot be speculated on since the pelleting procedures were not divulged by the manufactures of the pellets.

\section{$\underline{\text { Product Distribution }}$}

One of the potential benefits of wood catalysis is a shift in the product distribution towards more "valuable" products or products which will reduce the energy requirements of gasification. For example, if catalysis results in increased methane formation the resulting fuel gas will have a higher heating value and the gasification energy requirements will be lowered. An increase in the $\mathrm{H}_{2} / \mathrm{CO}$ ratio (by increasing the degree of the internal water gas shift reaction $\left.\mathrm{CO}+\mathrm{H}_{2} \mathrm{O} \rightarrow \mathrm{CO}_{2}+\mathrm{H}_{2}\right)$ will produce a gas more suitable for methanol synthesis or methanation. To determine how catalyses affects gas composition, a quick charge batch-solids fluid bed (BSFB) was used to allow operation with samples large enough (10 to $20 \mathrm{gms}$ ) to allow a reasonably accurate determination of product gas composition.

\section{Experimenta1 Variables and Measured Parameters}

The key experimental varlables were the catalyst and method of application and the gasification temperature. A gas sample was collected over a 10 minute sollds residence time period during which steam and helium were fed to the gasifier. Gasification temperature was the only gasifier operating parameter varied over in these tests. 


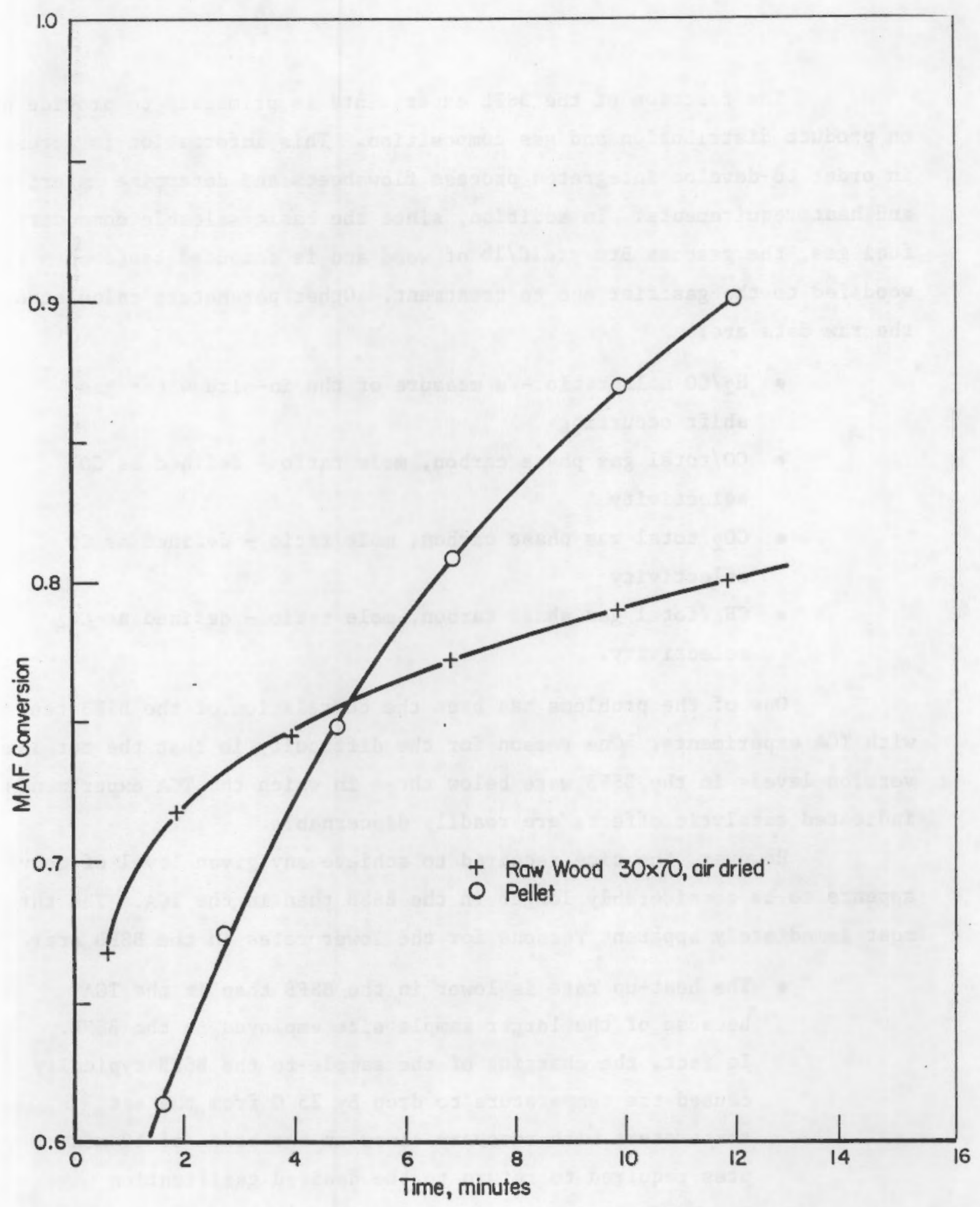

FIGURE 16. COMPARISON OF RAW WOOD AND PELLETS FROM BIOSOLAR CORPORATION. STEAM GASIFICATION AT $750^{\circ} \mathrm{C}$ 
The function of the BSFB experiments is primarily to provide data on product distribution and gas composition. This information is necessary in order to develop integrated process flowsheets and determine material and heat requirements. In addition, since the basic saleable commodity is fuel gas, the gaseous Btu yield/1b of wood and is computed based both on wood fed to the gasifier and to treatment. Other parameters calculated from the raw data are:

- $\mathrm{H}_{2} / \mathrm{CO}$ mole ratio - a measure of the in-situ water gas shift occurring

- Co/total gas phase carbon, mole ratio - defined as CO selectivity

- $\mathrm{CO}_{2} /$ total gas phase carbon, mole ratio - defined as $\mathrm{CO}$ selectivity

- $\mathrm{CH}_{4} /$ total gas phase carbon, mole ratio - defined as $\mathrm{CH}_{4}$ selectivity.

One of the problems has been the correlation of the BSFB tests with TGA experiments. One reason for the difficulty is that the total conversion levels in the BSFB were below those in which the TGA experiments Indicated catalytic effects are readily discernable.

However, the time required to achleve any given level of conversion appears to be considerably longer in the BSFB than in the TGA. The three most immediately apparent reasons for the lower rates in the BSFB are:

- The heat-up rate is lower in the BSFB than in the TGA because of the larger sample size employed in the BSFB. In fact, the charging of the sample to the BSFB typically caused the temperature to drop by $25 \mathrm{C}$ from the set temperature with recovery times on the order of 10 minutes required to return to the desired gasification temperature.

- The steam partial pressures used in the BSFB were lower because of steam generator limftations than in the TGA. However, "theoretically" this should not have a great effect on gasification rate. 
- Reactor products are present in significantly higher concentrations (though still low on an absolute basis) and may therefore suppress the gasification rate more in the BSFB than in the TGA. However, arguing against this proposition is the relatively large fraction of conversion that occurs during devolatilization and which should not be affected by product gas hinderance.

Presently, 1t seems the heat-up rate may be the biggest factor in causing differences between TGA and BSFB results. If this is the case, then the TGA is a better system for catalyst screening than the BSFB because of the higher heat-up rates. However, even In the TGA heat-up rates are much slower than they would be in a commercial reactor.

Because of the apparent sensitlvity of reactivity to heat-up rate, catalyst systems may behave differently and more effectively in continuous reactors. Thus, this may mean that the only rellable data will come from continuous reactors operating at steady state at heat-up rates and gas compositions that simulate commercial conditions.

In spite of the above problems, which resulted in the catalytic effects on rate being masked in the BSFB, the BSFB results indicated that all of the catalysts tested had a substantial effect on gas composition especially the water-gas shift reaction. In general, all the catalysts increased the $\mathrm{H}_{2} / \mathrm{CO}$ rat1o of the product gas.

Catalytic treatment methods employed were the same as those previously described. Thus the reader is referred to the previous section for a detailed discussion of the catalytic systems.

In addition to evaluating the effects of gasification temperature, catalysts type and application methods, limited studies were also conducted on solids residence time and wood type. In general, the tests were conducted with $30 \times 70$ mesh Oak particles at 620 to $820 \mathrm{C}, 150-160$ psig part1al pressure of steam and 10 minutes solids residence time.

A total of seven catalysts systems were investigated. The catalysts systems and the number of BSFB tests conducted on each system is noted below. 
(1) $\mathrm{CaO}-7$ (not included 3 runs with Sycamore, Sweetgum, and Mead I)

(2) $\mathrm{Na}_{2} \mathrm{CO}_{3} / \mathrm{CaO}-4$

(3) $\mathrm{Na}_{2} \mathrm{CO}_{3}-4$

(4) $\mathrm{Ca}\left(\mathrm{NO}_{3}\right)_{2}-5$

(5) $\mathrm{Ca}(\mathrm{OAC}) 2-1$

(6) $\mathrm{K}_{2} \mathrm{CO}_{3}-2$

(7) Wood Ash - 4

In addition, seven raw 0ak tests were completed. Most runs were conducted with an intial gasifier temperature of 650,700 or $750 \mathrm{C}$. However, because there were variations in the degree of temperature drop and the rate of temperature recovery during the run, results were correlated with the average gasification temperature.

In these experiments the catalysts were applied by:

(1) High temperature and pressure autoclave impregnation.

(2) Room temperature slurry saturation.

(3) Simulated spray application (conducted by spraying water on a dry mixture of catalysts and wood.

In each case, the samples were dried at $60 \mathrm{C}$ to approximately one percent moisture before testing.

During the gasification runs, the quantity of products produced were measured and samples were taken of the product gas and steam condensate. After the run was completed and the unft cooled, the char was collected. From the chemical analysis and product quantity data carbon conversions to gases and liquids, total MAF conversion, gas and Btu ylelds, product gas heating values and carbon balance closures were calculated. The effectiveness of treatment was evaluated by comparison of the carbon conversion and Btu ylelds of the treated samples (adjusted to reflect for any losses encountered during treatment) to raw oak samples gasified at similar temperature, steam pressure, and residence times. 
Carbon Conversion. Gasification temperature had the most significant effect on carbon conversion. The carbon conversion data is summarized in Figure 16 for the various catalysts and treatment methods employed. An attempt was made to draw curves to illustrate the effect of various catalytic systems. While there is considerable scatter and only a few data points for each system, there appears to be the following trends.

- Catalytic effects are most pronounced above $700 \mathrm{C}$.

- The $\mathrm{Na}_{2} \mathrm{CO}_{3} / \mathrm{CaO}$ system appears to be the most effective. (Remember that the TGA results indicated that $\mathrm{CaO}$ alone was a better catalyst than the $\mathrm{Na}_{2} \mathrm{CO}_{3} / \mathrm{CaO}$ system.)

- Carbon conversion to liquids does not appear to be greatly affected by the catalytic system employed and in addition the liquid yields decline with increasing temperature.

- At lower temperatures (less than $700 \mathrm{C}$ ) there is no discernable effect of catalyst on carbon conversion. (Again different than TGA results which show that (1.e., Figure 17) catalytic effects on rate are greater at $650 \mathrm{C}$ than at 750 C.)

$\mathrm{H}_{2} / \mathrm{CO}$ Mole Ratio. All the catalytic systems studied show a pronounced effect on the water-gas shift reaction $\left(\mathrm{CO}+\mathrm{H}_{2} \mathrm{O}+\mathrm{CO}_{2}+\mathrm{H}_{2}\right)$. This is illustrated in Figure 18 where the mole ratio of $\mathrm{H}_{2} / \mathrm{CO}$ is plotted against temperature. As temperature increases so does the ratio of $\mathrm{H}_{2} / \mathrm{CO}$. Since the water-gas shift reaction (as written above) is somewhat exothermic, these data Imply that the system is not at equilibrium with respect to this reaction but that the rate of the $\mathrm{CO}+\mathrm{H}_{2} \mathrm{O}$ reaction is accelerated by the catalysts present. Because of the excess steam in these tests, the actual equilibrium ratios of $\mathrm{H}_{2} / \mathrm{CO}$ are probably much higher than those measured. of all the catalytic systems evaluated, wood ash seems to affect least the water-gas shift reaction. However, even with wood ash the $\mathrm{H}_{2} / \mathrm{CO}$ ratios are substantially above those of raw wood. 


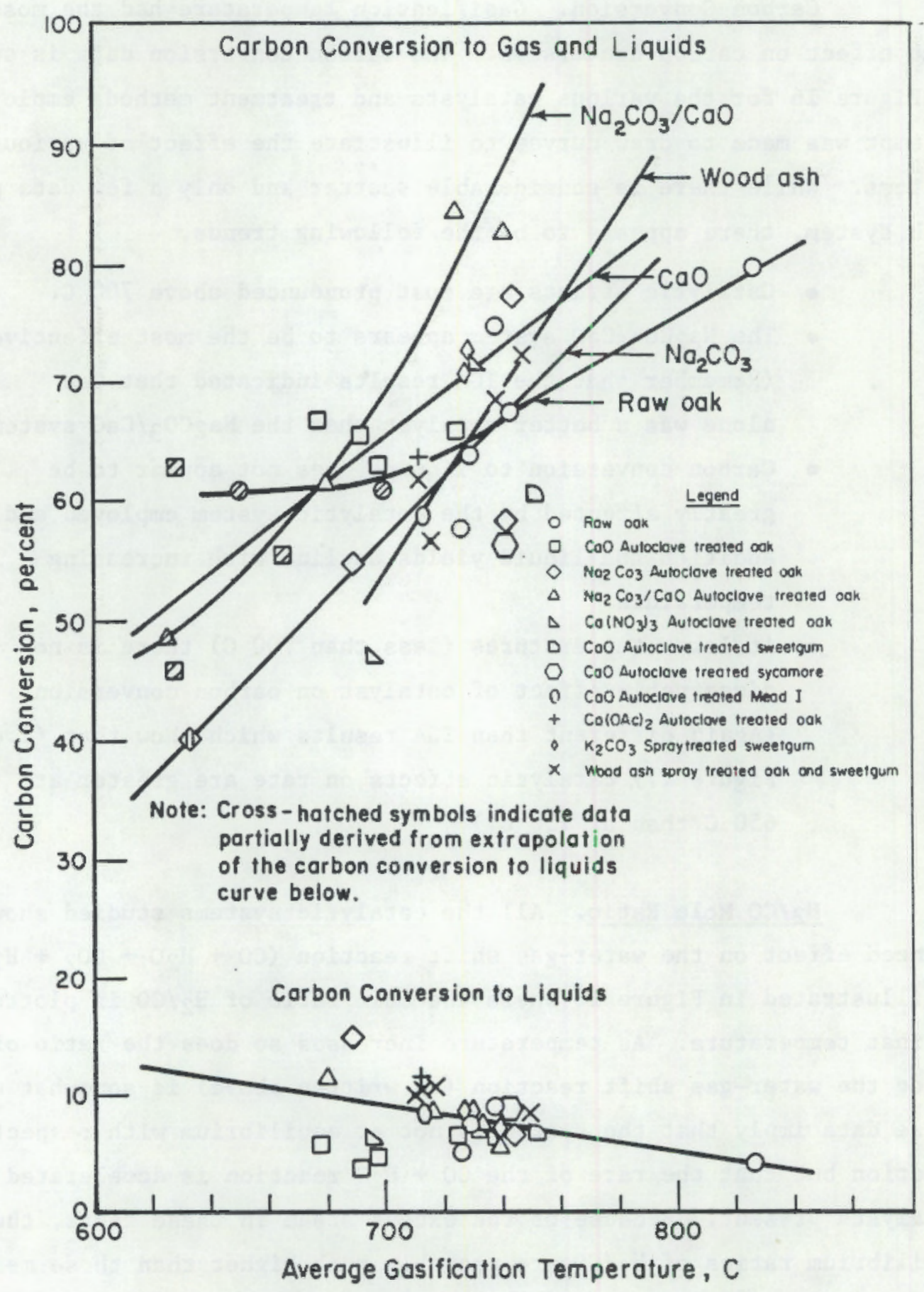

FIGURE 17. TOTAL CARBON CONVERSION TO LIQUIDS VERSUS GASIFICATION TEMPERATURE AS A FUNCTION OF WOOD CATALYSTS 


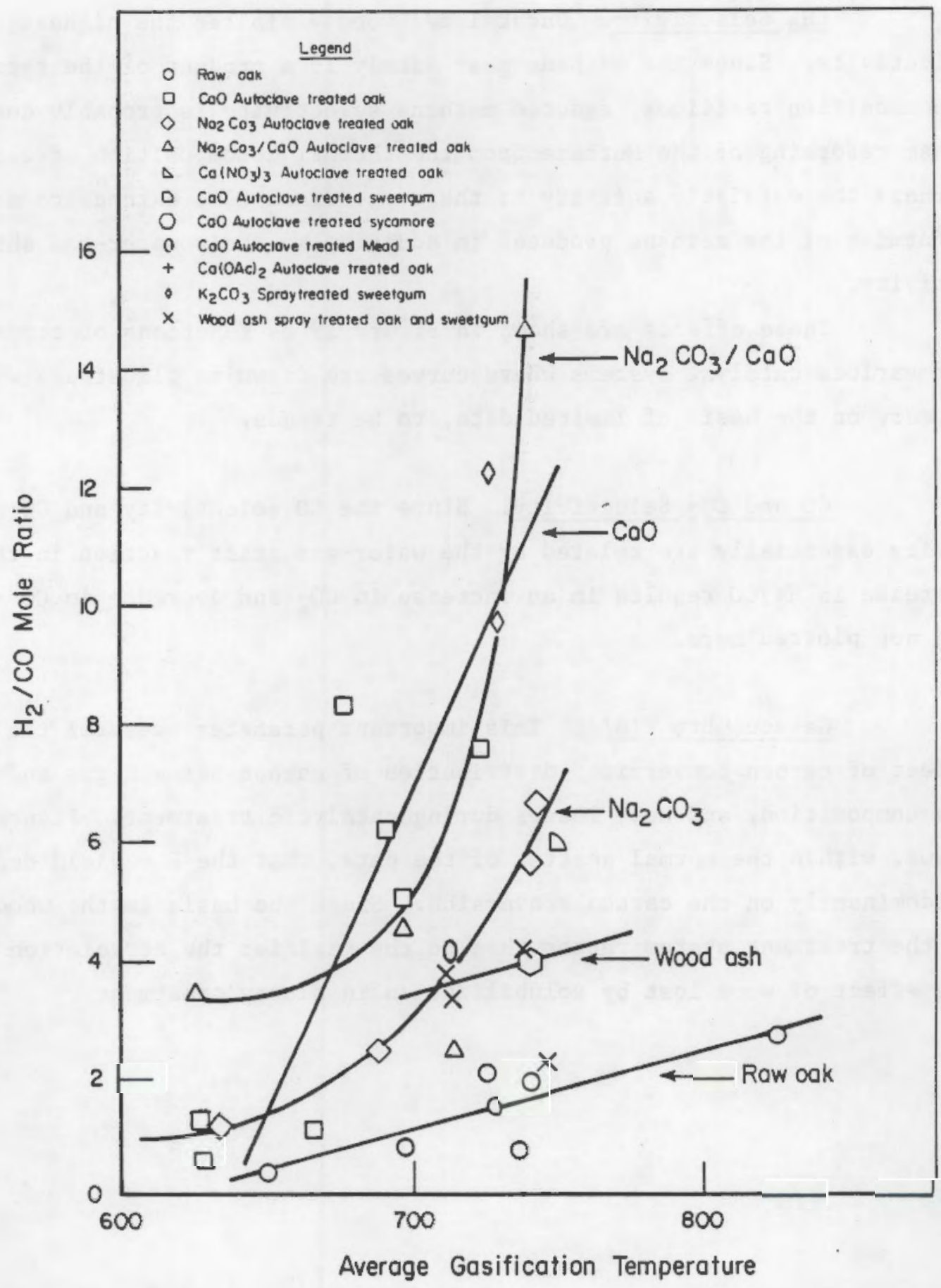

FIGURE 18. $\mathrm{H}_{2}$ /CO RATIO VERSUS GASIFICATION TEMPERATURE AS A FUNCTION OF WOOD CATALYSTS 
$\mathrm{CH}_{4}$ Selectivity. Uncatalyzed wood exhibited the highest $\mathrm{CH}_{4}$ selectivity. Since the methane most likely is a product of the thermal decomposition reactions, reduced methane selectivity is probably due to steam reforming of the methane from the thermal decomposition of wood. Perhaps the catalytic activity of these materials also extends to steam reforming of the methane produced in addition to their water-gas shift activity.

These effects are shown in Figure 19 as functions of temperature for various catalyst systems where curves are drawn to illustrate what appear, on the basis of limited data, to be trends.

$\mathrm{CO}$ and $\mathrm{CO}_{2}$ Selectivity. Since the $\mathrm{CO}$ selectivity and $\mathrm{CO}_{2}$ selectivity essentially are related by the water-gas shift reaction in that an increase in $\mathrm{H}_{2} / \mathrm{CO}$ results in an increase in $\mathrm{CO}_{2}$ and decrease in co they are not plotted here.

Gaseous Btu Yield. This important parameter measures the combined effect of carbon conversion, distribution of carbon between gas and liquid, gas composition, and wood losses during catalytic treatment. Figure 20 shows, within the normal scatter of the data, that the Btu yield depends predominantly on the carbon conversion. Since the basis is the wood fed to the treatment system rather than to the gasifier the correlation includes the effect of wood lost by solubilization in slurry treatment. 


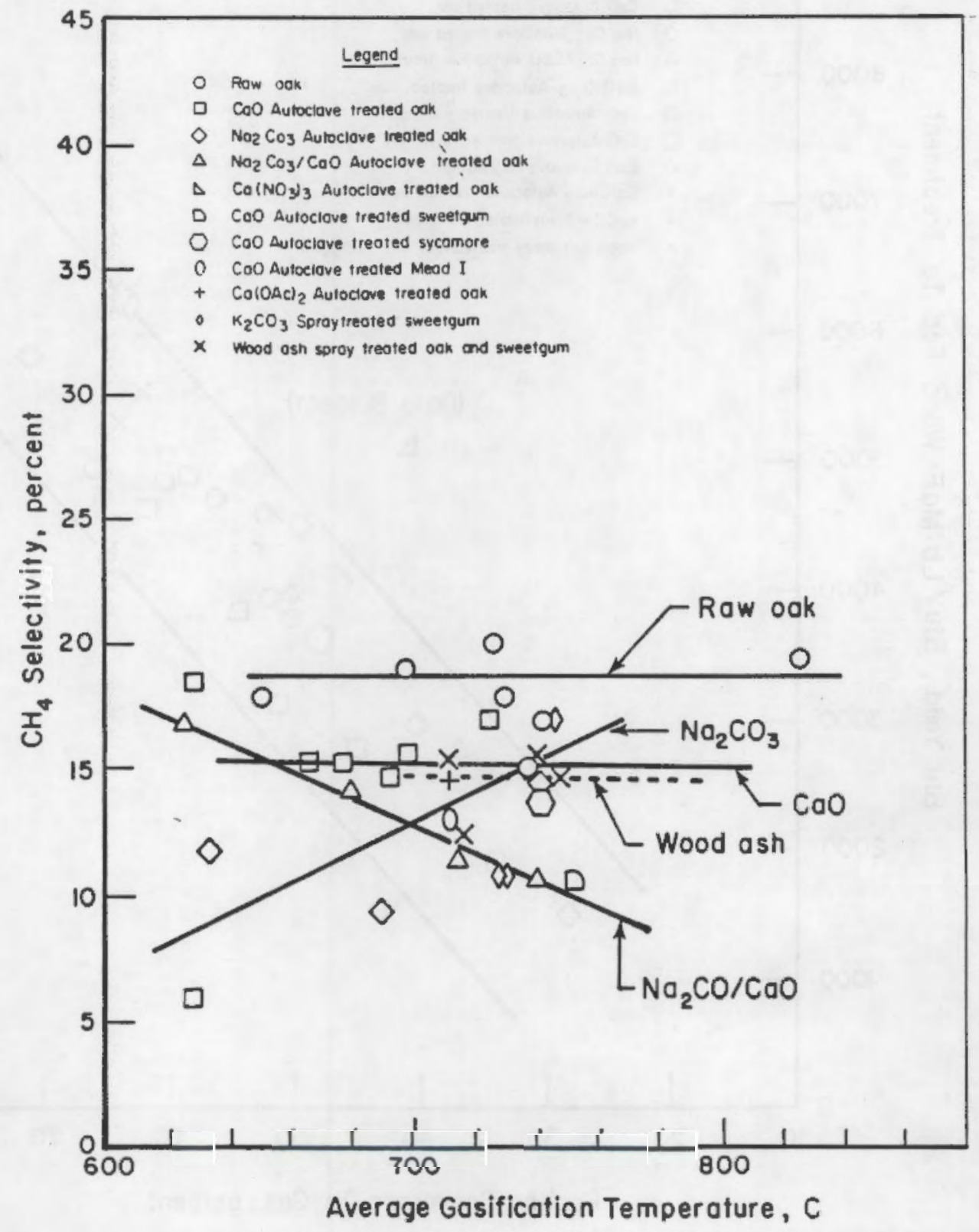

FIGURE 19. $\mathrm{CH}_{4}$ SELECTIVITY VERSUS GASIFICATION TEMPERATURE AS A FUNCTION OF WOOD CATALYSTS 


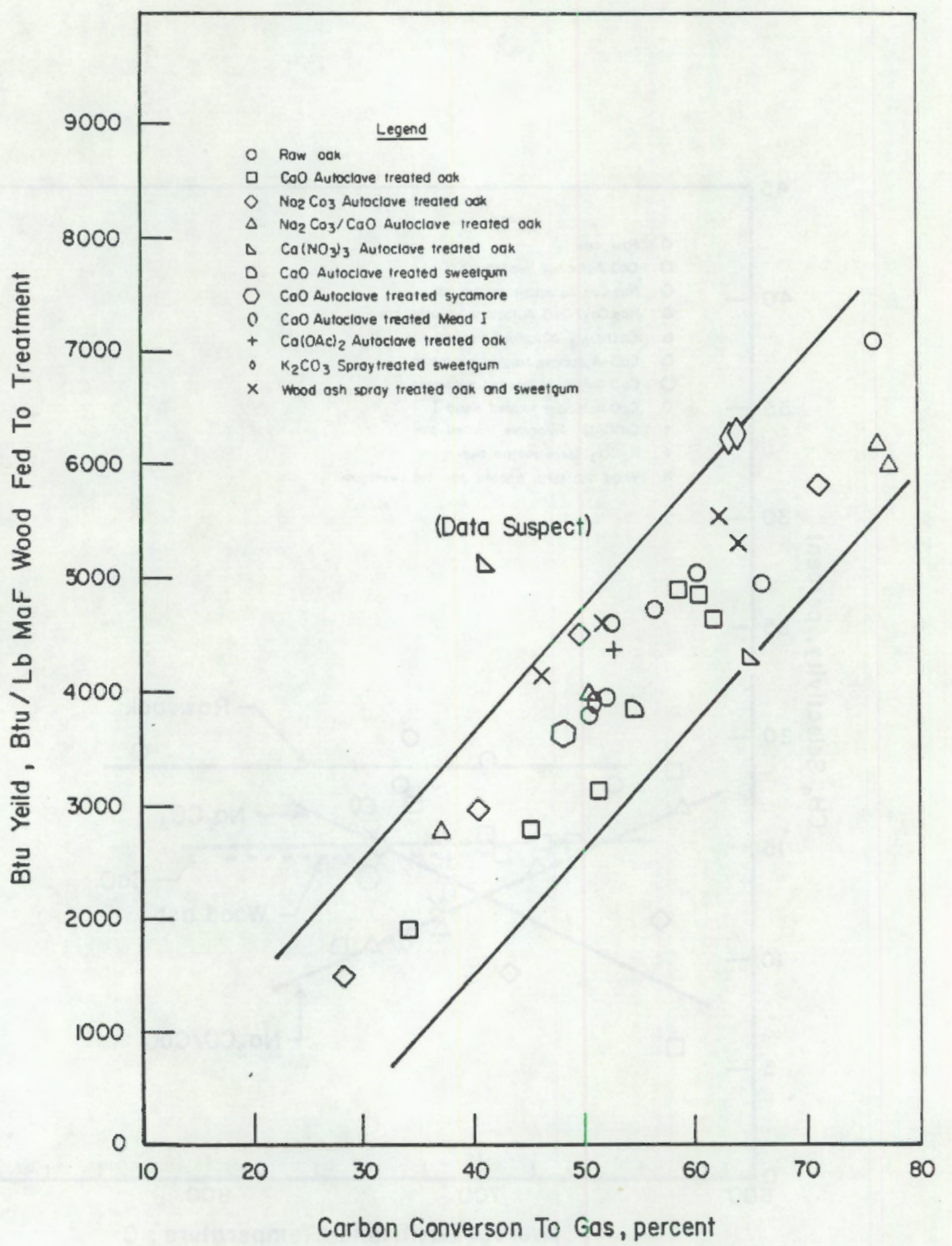

FIGURE 20. BTU YIELD VERSUS CARBON CONVERSION AS A FUNCTION OF WOOD CATALYST 
Obviously, the easlest approach to wood gasification would be to utilize some existing gasification system. However, examination of existing coal gasifiers indlcates that there are serious drawbacks to simply switching from coal to wood residues. Perhaps, the only coal gasification system that would be directly applicable would be the entrained reactor but this would require grinding all the wood to fine particies to permit thelr entrainment. This grinding would result in a very significant cost penalty to the process.

In the paragraphs below, various types of gasification systems are examined for their potential application for the gasification of wood. However, before discussing the specific gasifier types it is worthwhile to consider the potential that exists for the development of 1mproved gasifier systems.

The gasification rate measurements reported here as well as elsewhere all attest to the extremely high reactivity of cellulosic materials such as wood when compared with materials such as coal. In addition, because of the extremely low sulfur level of wood, it is possible to use the gas directly without first requiring sulfur cleanup. Thus, a plant gasifying wood for fuel gas will only require wood handling and feeding equipment In addition to the gasifier; If the gas is to be used directly eliminating recovery, dust/water removal, and water treatment systems. Therefore, a plant gasifying wood wll be considerably stmpler than a coal gasification plant and the gasffler will represent a larger fraction of the total plant investment for the wood gasification plant compared to the coal gasification plant. Therefore, the development of a higher throughput* gasiffer should allow a much greater potential for reducing overall conversion costs for a wood gasification plant compared to a coal gasification plant.

*Throughput is defined here as the specific solids throughput (STP) = Ibs wood $/ \mathrm{ft}^{2}$ (reactor cross section) per hr. It is this measure of throughput that determines the necessary reactor diameter to process a given amount of solids. STP 1s therefore more of an indicator of reactor costs than other parameters representing throughput. 
Some of the features desirable and perhaps necessary in a gasifier handling biomass-type feeds are the ability to:

(1) Operate at high enough gas velocities to permlt solids feeding at the throughputs (1bs/ft ${ }^{2}$ reactor-hr) made posstble by the high reactivity.

(2) Phystcally handle the flbrous, lcw bulk denstty, and oft times irregular feeds typical of many kinds of biomass materials. For example wood may contain branch Eragments, sawdust, chips and leaves.

(3) Allow the biomass material to be used with minimal front end preparation so as to minimize feed costs. Thus, the reactor should be able to handle the feed without elther requiring 1 t to be finely ground, pelletized, or preseparated.

\section{Reactor Throughput}

Examination of the factors that can linit reactor throughput indicates that these factors can be divided into the following categories.

(1) Solids "reactivity".

This determines the solids residence time required to achieve a given converston level.

(2) Maximum allowable gas velocity.

For example in a fluid bed, this would be a reasonable multiple of the mintmum Eluidization velocity.

(3) Solids velocity and solids concencration in the reactor. For example, in a packed moving bed, the downward velocity of the solids in the bed is limteed by frictional forces between particles and between the particles and wall. Thus, if the maximum downward solids velocity is $U_{\text {solids }}(E t / s e c$ ) and the density of the solids in the bed is given by psolids (lbs/ $\mathrm{ft}^{3}$ ) the maximum throughput is Usolids $x$ psolids (1bs/ft $\mathrm{t}^{2}-\mathrm{sec}$ ). 
In certain specialized reactor systems, other factors may control throughput such as heat transfer through reactor walls or even mechanical movement of solids by a screw for example.

In order to provide a quantitative perspective on the above potential throughput limicing factors, some calculations were made using data generated in the batch fluld-bed tests to determine reasonable gas/solids ratios typical of wood gasification.

These calculations Indicate that for a steam gasifier, the ratio of product gas to wood fed is approximately $0.06 \mathrm{Ib}$-moles of product gas/lb wood fed. Of course, this ratio is affected by gas yield and steam decomposition but $1 \mathrm{n}$ any given system it will be relatively constant. Thus, at any given temperature and pressure the volumetric flow rate of gas per $1 b$ of wood is fixed. With the above gas/feed solids ratio together with the solids residence time required for the desired conversion, the gas velocity necessary to achieve a solids throughput that is limited by the reactivity of the solids can be calculated.

For example, the specific solid throughput is given by

$$
\frac{F_{W}}{A_{R}}=\frac{h E_{W} P_{W R}}{t_{W}\left(1-Y_{T}\right)}
$$

where

$\mathrm{F}_{\mathrm{W}}=$ wood feed rate to reactor, $1 \mathrm{bs} / \mathrm{hr}$

$A_{R}=$ cross sectional area of the reactor, $\mathrm{ft}^{2}$

$\mathrm{h}=$ bed hefght, ft

$E_{W}=$ volume fraction of bed occupied by gasifying char

$\rho_{W R}=$ density of char in reactor

$\mathrm{t}_{\mathrm{W}}=$ residence time, hrs

$\mathrm{Y}_{\mathrm{T}}=$ total fractional converston.

Substituting some reasonable values for the above parameters as determined by bench-scale gasfflcation tests and our cold-model tests indicate that a reasonable reactor configuration operating with uncatalyzed wood could operate at a specific solids throughput of

$\frac{20 \mathrm{ft} \times .20 \times 40 \mathrm{lbs} / \mathrm{ft}^{3}}{0.2 \mathrm{hr} \times(1-.90)}=8000 \frac{1 \mathrm{bs}}{\mathrm{ft}^{2}-\mathrm{hr}}$ 
To operate a reacror at the above sollds throughput will require a gas velocity given by the expression

$$
\frac{U_{g} P}{a R T}=\frac{F_{W}}{A_{R}} \text {. }
$$

where

$$
\begin{aligned}
\mathrm{U}_{\mathrm{g}} & =\text { the gaslfler gas velocity, } \mathrm{ft} / \mathrm{hr} \\
\mathrm{P} & =\text { the gasifier pressure, abs. atm } \\
\mathrm{a} & =1 \mathrm{~b}-\text { moles gas/lb-wood } \\
\mathrm{R} & =\text { gas constant } 0.73\left(\mathrm{ft}^{3}\right)(\mathrm{atm}) /(1 \mathrm{~b} \text {-mole })\left({ }^{\circ} \mathrm{R}\right) \\
\mathrm{T} & =\text { gasifier temperature, }{ }^{\circ} \mathrm{R} .
\end{aligned}
$$

As mentioned above, a 2.06 lb-moles/lb-wood. Substituting a gas1fler temperature of $750 \mathrm{C}\left(1842^{\circ} \mathrm{R}\right)$ and an operating pressure of $100 \mathrm{psig}$ (7.8 atm abs.) 1nto Equation 2 indicates that the reactor would have to operate at a

$$
\mathrm{U}_{\mathrm{g}}=\frac{8000 \times .06 \times .73 \times 1842}{7.8}=82748 \mathrm{ft} / \mathrm{hr} \text { or } 23 \mathrm{ft} / \mathrm{sec}
$$

in order to explote the reactivity of even uncatalyzed wood.

Thus, the above calculations demonsrate that high gas velocities are necessary to prevent gas velocity from limiting solids throughput

\section{Utilization of Extsting Gasification Reactor Systems}

\section{Fludd Beds}

Inspection of the char remaining frot our BSFB tests reveal that 1t would be extremely difflcult to operate a fluid-bed gasifier in which the char was the fluldized phase because of 1ts lightness and friability after gasification. Thus, if a fluld bed is to be employed it must probably employ an inert materlal that is Iluidized rather than the wood itself.

One example of such a fluid bed is the Baflie Process which uses a fluldized sand bed for conversion. Reported gas veloctties for the Bailie Process are on the order of 1 to $2 \mathrm{ft} / \mathrm{sec}$ and the operating pressure is one 
atmosphere. In a concepcual design and economic evaluation, (2) a specific solids rate equivalent to about 250 lbs/ft ${ }^{2}-h r$ was used co size a commercial reactor.

The Baille Process is based on the circulation of sand or other fluidized medium between two fluid beds. In one bed, combustion occurs and the heated sand is transferred to another bed in which the combustion heat is used to pyrolyze and/or gastfy the destred feedstock. In principle, the Bailie Process can use any fluidized medium in the above fashlon. Therefore, the allowable gas velocity for the Bailie Process is perhaps based more upon the particular fluid-bed medium selected than on any fundamentaI 11mitation. In the Baille Process, the transfer of solids from the fluldized gasifier to the combustor means that the solids going to the combustor wlll contaln feed material of varlous conversion levels depending on the residence time distribution in the bed.

With biomass cype materials that are highly reactive, the race of pyrolysis is probably limited by the rate of heat transfer if the dimensions of the particle are such that there are no 1nternal temperature gradients in the particle. Thus, for many macerlals such as paper (where the critical dimension is its thickness) or finer particulate blomass, the fluld bed will cons1st of the fluldized medium and "completely" pyrolyzed char.

However, in the case of forest residue and other wood feedstocks, 1t will probably be necessary to feed coarser chips in order to maintain reasonable feed preparation costs. Therefore, the fluid bed will contain wood with conversion levels that vary from fresh chips with only the outs1de converted to completely pyrolyzed (but still gasifylng) fragments. Transfer of material from a fluid bed containing wood at a varfety of conversion levels w11 result in removal of much partially converted wood thereby lowering overall gas production per unit of wood fed. 
Utilization of gravitating packed beds of wood gasification would be limited by the downward veloctty of the gravitating bed. In addition, there is the question of the behavior of the very light frlable ash formed by wood gasiffcation in the reactor bottom. At any rate, even wth coal, the throughputs in gravitating packed bed reactors are ordinarily Iow (on the order of $200 \mathrm{lbs} / \mathrm{ft}^{2} \mathrm{hr}$ ) and they cannot colerate fines. Gasifiers utillzing forest restdue materials should have the ability to operate with feeds ranging from sawdust to chips to the 1rregular needles, branches, leaves and other assorted materials. Therefore, for unsized materials, the utilization of packed beds may be limited.

\section{Entrained Gasifiers}

Entrained gasifiers certainly represent a workable option but they have the following drawbacks.

- The necessity to reduce everything to a fine entrainable particle size range 2100 mesh whtch would increase solids preparation costs.

- The temperatures required are very high because the solid residence time is on the order of fractions of a second.

- They operate at very low solids concentrations in the reactor.

- Exit temperatures are high and there is no way of recycling this heat to the gasifier entrance to reduce net gasifler energy requirements.

The Mu1ti-Solid Flu1d-Bed Gasifier

A gasifier that has characteristics that make its utilization extremely attractive for the gasification of forest residues is being developed by Batte1le-Columbus. This gasifier is the so-called "multi-solid fluid-bed" 
developed by Battelle-Columbus for the combustion or gasification of solids that are irregular, sticky or otherwise hard to handle in "conventional" reactor systems and is shown in Figure 21.

Raw or catalyzed wood is injected into the multi-solid gasifier with steam. Heat for gasification is provided by recirculating hot sand which is entrained through the fluidized bed. The exiting sand plus the gasified char are removed by a cyclone and fed into a fluidized combustion zone where the remainder of the char is burned to provide the heat for gasification and other plant heat requirements. The basic multi-solid system which employs a dense phase fluid bed through which another solid phase is entrained to either remove heat (in the case of combustion) or to provide a source of heat (in the case of gasification) has been granted a U.S. patent.

The advantages listed below should result from the utilization of the multi-solid fluld bed.

- High heat-up rates should allow maximum conversion to gases and minfmize formation of residual char.

- Very high reactor throughputs are possible because wood reactivity will be the limiting factor rather than heat transfer through walls or other mechanical constraints.

- A methanation catalyst can be employed as the densephase fluid bed thus providing the potential of maximizing direct $\mathrm{CH}_{4}$ yields, increasing overall thermal efficlency and reducing investment costs.

- Retention times for finer wood such as sawdust will be far higher than would be estimated based on gas velocity alone because the many collislons the wood particles make in moving through the dense-phase fluld bed.

- Gasification heat requirements can be supplied by combustion of the char with air in a separate vesse1 thus eliminating the need for an oxygen plant. 


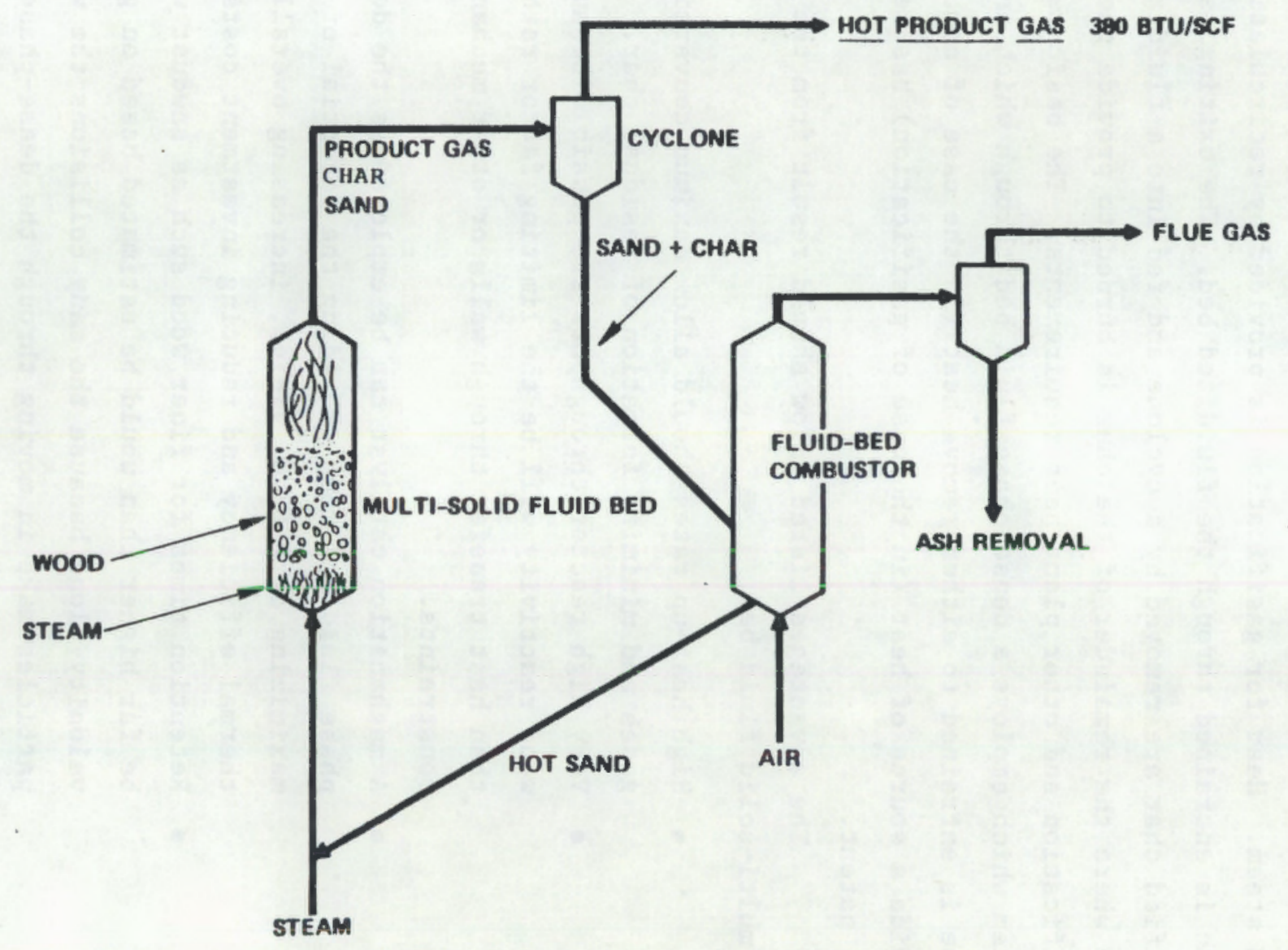

FIGURE 21. SCHEMATIC OF MS-FBG PROCESS 
- Reduced $\mathrm{CO}_{2}$ ylelds brought about by eliminating oxygen in the gasifier increase the possibility of using unscrubbed gas directly thus further increasing thermal efficiency and reducing overall plant investment requirements.

- Utilization of coarse chips and irregular pieces of wood is possible as evidenced by both the coldmodel experiments described above and by the utilization of coal ranging from 8 mesh to $1-1 / 4$ inch chunks In the multi-solid fluid-bed combustor.

- The fluidized-bed system is operating in "turbulent" fluidization regime rather than "bubbling" fluidization regime. Thus, process scale-up problems can be great $1 y$ reduced.

Generically, the MSFB is a gasification process ut1l1zing an inert solid circulating between a combustion vessel and a gasifier to supply the heat for gasification as in the Bailie Process(2) (and several others developed specifically for coal gasification).

The real basic, fundamental, and critically important difference between Prof. Ballie's Process and the MSFB is that in the MSFB system removal of solids from the MSFB is by entrainment whereas the Bailie Process must remove the solids from the fluid bed itself because the fluidized solids are clrculated between vessels. This means that the solids transferred from the conversion reactor in the Ballie Process will be representative of the solids in the fluid bed and contain feed material of various conversion levels depending on the residence time distribution in the bed. Since in the MSFB solids removal is by entrainment, the bed composition will be considerably different than the material removed. The MSFB will contain the dense-phase fluid-bed medium and cofluidized gasifying wood chips which will attrite upon conversion and be entrained out of the bed. Thus, the MSFB can contain a reasonably high inventory of carbon in the form of unconverted wood without incurring the carbon losses that would be experienced in a conventional fluid bed. Since the carbon gasification rate will 
be proportional to the carbon inventory in the bed, a higher carbon inventory allows higher gasification rates. At steady state, the carbon feed rate to the bed must be equal to the gasification rate plus the carbon in the char exiting the bed. In the MSFB, the only char exiting the fluid bed is that highly converted enough to be atcrited and elutriated. Thus, the MSFB allows high gasification rates without excessive carbon withdrawal from the bed as char.

\section{MSFB Cold-Model Tests}

In order to evaluate the possibility of achieving the high gas velocities estimated above to be necessary in order not to have throughput gas velocity limited and to determine the "quality" of gas-solids contacting in a MSFB, some cold-model tests were run using wood chips in a 4-inch I.D. transparent plastic fluidized-bed facility.

The following tests were made in the ambient test facility.

- Wood chips were used alone in order to determine whether they could be fluidized and at what gas velocities.

- Wood chips were added to a bed of alumina which was fluidized.

- An entrained feed of finer sand was added to the fluidized alumina bed containing the wood chips.

With the wood chips alone, severe channeling occurred or the chips had a tendency to interlock, bridge, and then, upon further increases in gas velocity, to blow out of the reactor as a slug. The behavior exhibited was random and unpredictable and 1 was concluded that it would be impossible to fluidize the chips or to operate at the necessary gas velocities. Utilization of wood chips alone would require much lower gas veloctties and the gasifier would have to operate as a gravitating bed. Of course, if the wood mixture contained fines such as sawdust the throughput would be further reduced.

Addition of the wood chips to a fluidized bed of 8-mesh alumina pellets operating at gas velocities of about $20 \mathrm{ft} / \mathrm{sec}$ produced good 
fluidization. However, the bed did have a tendency to slug which was probably due to the relatively small tube diameter and therefore perhaps slugging wouldn't be a problem in larger diameter reactors.

Addition of 50 mesh sand to the fluidized alumina-wood chip bed resulted in the sand being entrained through the flufd bed and greatly improved fluidization. The bed was completely stable with uniform solids distribution and all traces of slugging disappeared. Thus, it is anticipated that even in large reactors the presence of the entrained solid phase would allow more stable fluidization and the deslgn of reactors with larger $L / D$ ratios than may otherwise be possible.

In the MSFB System, the function of the entrained sand is to provide the endothermic heat of gasification. Thus, the cold model tests demonstrated that in addition to providing the gasification heat, the entrained solld phase also improves fluidization. 


\section{COST FEASIBILITY ANALYSES}

In order to provide a basis for comparing the cost advantage of using the catalysts found effective during the bench-scale studies described above a base-case cost evaluation was made using uncatalyzed wood gasifled in the MSFB gastfier.

\section{Intermediate Btu Gas}

The flowsheet for a plant producing a quenched intermediate-Btu gas is shown in Figure 22. The basic assumptions made in developing the flowsheet are listed in Table 3 for a 500 tpd plant. Other plant sizes and process options were scaled from the 500 tpd plant. The process options presented include:

- 500 tpd (oven dry) - intermediate-Btu gas quenched

- 1000 tpd (oven dry) - intermediate-Btu gas quenched

- 1000 tpd ) oven dry) - intermediate-Btu gas - gas used hot

- 5000 tpd )oven dry) - SNG.

The last case involves an extremely large plant (based on wood fed) and is presented to illustrate the larger scale required to produce SNG at approximately the same gas price as an intermediate-Btu gas. The increase in gas processing steps required to produce SNG compared to an intermediateBtu gas require larger plants to reduce the cost per unit of gas produced. Because the 500-tpd plant was used as the base case from which the other Intermediate-Btu gas cases were scaled, Investment, capital requirements, and operating costs are tabulated for the 500 tpd plant.

Total plant investment is shown in Table 4 and the total capital requirements in Table 5. Operating costs for the 500 tpd plant are shown in Table 6. 


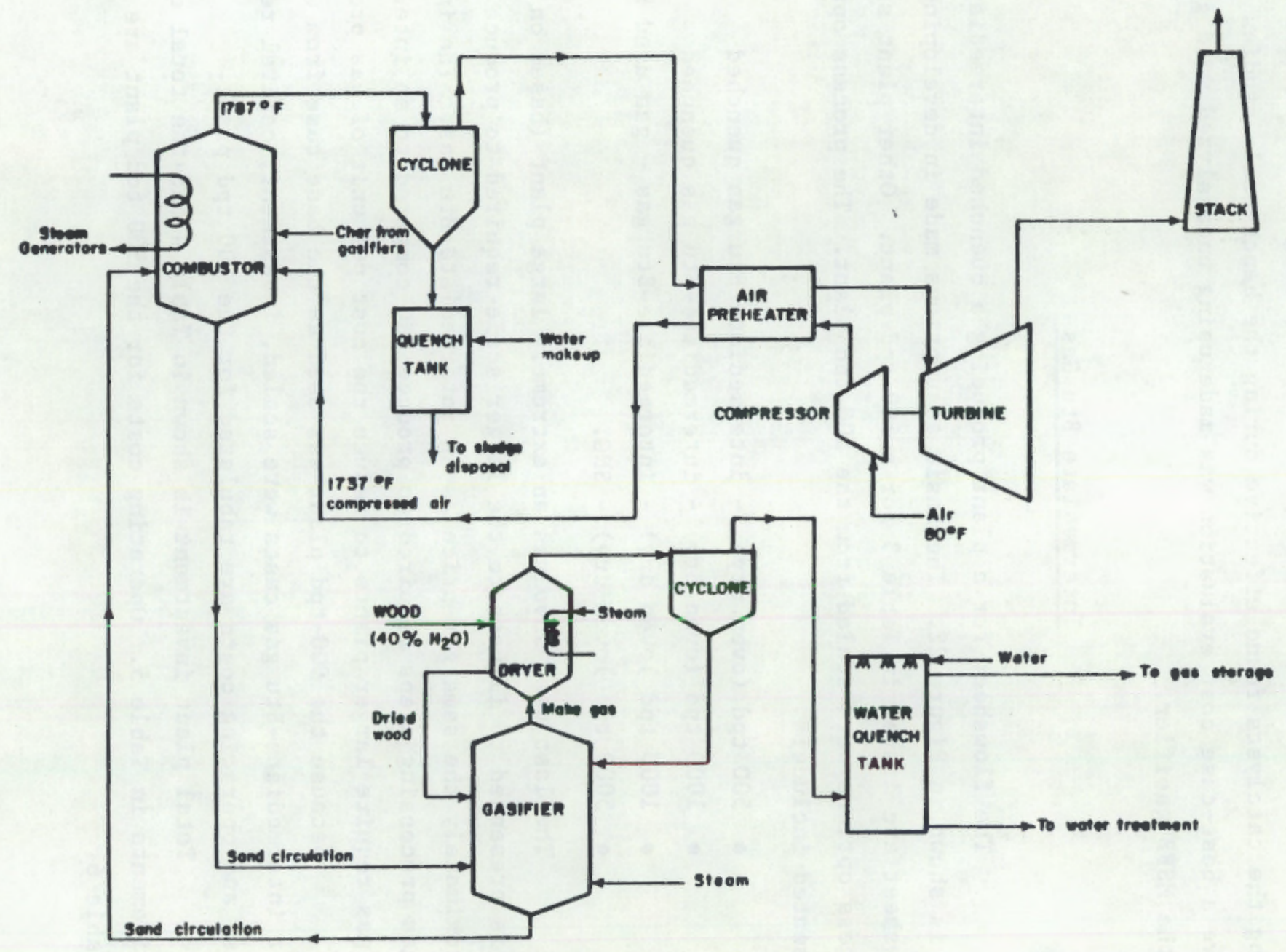

FIGURE 22. PROCESS FLOW DIAGRAM FOR INTERMEDIATE-BTU GAS FROM WOOD PLANT 
1. 500 tons per day dry feed to a single train plant - plant produces intermediate Btu gas (a total of 504.5 tpd are required to satisfy the overall plant energy requirements).

2. Feed composition to the plant:

$$
\text { wt \% }
$$

$\begin{array}{lr}\mathrm{C} & 29.82 \\ \mathrm{H} & 3.24 \\ \mathrm{~S} & 0.06 \\ \mathrm{O} & 23.58 \\ \mathrm{~N} & 0.12 \\ \text { Ash } & 3.18 \\ \text { Moisture } & 40.00\end{array}$

3. Moisture-free wood heating value $=4.65 \mathrm{kcal} / \mathrm{g}(8364.5 \mathrm{Btu} / 1 \mathrm{~b})$

4. Carbon conversion $=78$ percent

5. Gasifier temperature $=750 \mathrm{C}$

6. Combustor temperature $=975 \mathrm{C}$

7. Operating pressure $=100$ psig

8. Steam required to gasifier $=0.1183 \mathrm{lb}$ steam $/ 1 \mathrm{~b}$ MF wood

9. C1rculating burden $=264 \mathrm{~T} / \mathrm{hr}$

10. Combustor a1r requirements $=10$ percent excess

11. Location $=$ Gulf Coast area

12. Size of wood feed delivered to the plant gate $-1-1 / 2^{\prime \prime} \times 1-1 / 2^{\prime \prime} \times$ 1/4"; no feed preparation costs charged to plant

13. Product Gas Composition

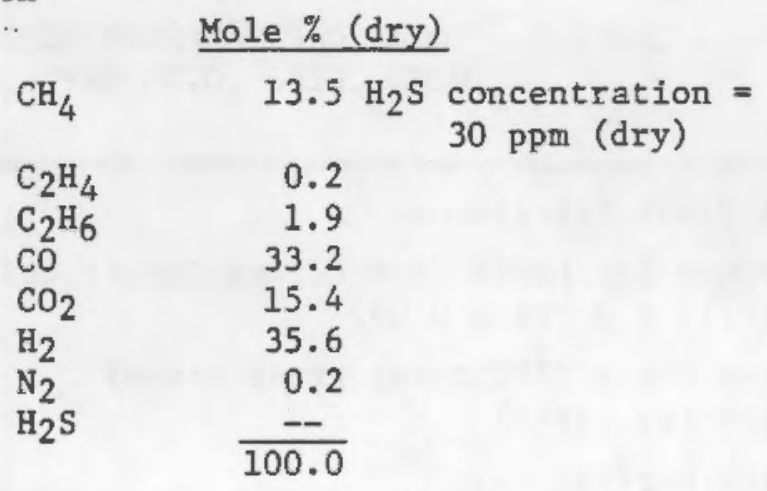

$\mathrm{HHV}=394 \mathrm{Btu} / \mathrm{scf}$

14. Gas Yield - 14.56 MM Btu/ton wood to gasifier

15. 20 days feed storage

16. No product storage capabilities

17. Plant thermal efficiency $=86.3$ percent (based on product gas) 
TABLE 4. TOTAL PLANT INVESTMENT - 500 TPD WOOD CHIPS (OVEN DRY)

\begin{tabular}{lr}
\hline \multicolumn{1}{c}{ Plant Section } & \multicolumn{1}{c}{$\$$} \\
\hline Feed Storage & 41,000 \\
Feed System & 958,600 \\
Gasification & 346,100 \\
Gas Quench & 772,600 \\
Combustion & 306,300 \\
Ash Disposal & 503,200 \\
Compression & 701,200 \\
Water Treatment & 290,700 \\
Electrical Generation & 745,600 \\
Cooling Tower & 66,500 \\
Pumps & 64,000 \\
General Utilities & 532,900 \\
(10\% of Installed Cost) & $5,329,200$ \\
$\quad$ Total Insta1led Cost & 591,500 \\
$\quad$ Contractor's Fee (11.1\%) & $5,920,700$ \\
$\quad$ Subtotal & 888,100 \\
\hline Contingency (15\%) & $6,808,800$ \\
\hline TOTAL PLANT INVESTMENT & \\
\hline \hline
\end{tabular}

TABLE 5. TOTAL CAPITAL REQUIREMENT - 500 TPD WOOD CHIPS (OVEN DRY)

\begin{tabular}{lr}
\hline Total Plant Investment & $\$ 6,808,800$ \\
$\begin{array}{l}\text { Allowance for Funds Used During Construction } \\
\text { (T.P.I. x } 3 \text { yrs x 0.09) }\end{array}$ & $1,838,400$ \\
$\begin{array}{l}\text { Startup Costs (20\% total gross annual } \\
\text { operating costs) }\end{array}$ & $1,105,000$ \\
Working Captial & \\
(1) Raw materials (14-day 1nventory wood - & 117,700 \\
(2) Materials and supplies (0.9\% T.P.I.) & 61,300 \\
(3) Net receivables (1/24 annual gas revenue) & 311,200 \\
\hline \hline
\end{tabular}


TABLE 6. ANNUAL OPERATING COSTS - 500 TPD

WOOD CHIPS (OVEN DRY)

\begin{tabular}{|c|c|}
\hline Raw Materials ( $840.8 \mathrm{~T} / \mathrm{D} \times \$ 10 /$ ton $\times 365$ days $\times 0.9)$ & $\$ 2,762,000$ \\
\hline Purchased Water $\left(1 \times 10^{6} \mathrm{gal} \times \$ 0.70 / \mathrm{M} \mathrm{gal}\right)$ & 700 \\
\hline \multicolumn{2}{|l|}{ Labor } \\
\hline $\begin{array}{l}\text { Process Operating Labor ( } 12.5 \mathrm{man} / \mathrm{shift} \mathrm{x} \\
8760 \mathrm{man}-\mathrm{hr} / \mathrm{yr} \times \$ 8.00 / \mathrm{man}-\mathrm{hr})\end{array}$ & 876,000 \\
\hline *Maintenance Labor (Total maintenance x 60\%) & 245,100 \\
\hline $\begin{array}{l}\text { Superviston ( } 20 \% \text { operating labor \& maintenance } \\
\text { labor) }\end{array}$ & \\
\hline Administration ( $60 \%$ of labor) & 807,200 \\
\hline \multicolumn{2}{|l|}{ Supplies } \\
\hline Operating ( $30 \%$ of process operating labor) & 262,800 \\
\hline kMaintenance (Total ma1ntenance $\times$ 40\%) & 163,400 \\
\hline Local Taxes and Insurance ( $2.7 \%$ of T.P.I.) & 183,800 \\
\hline TOTAL ANNUAL OPERATING COSTS & $\$ 5,525,200$ \\
\hline
\end{tabular}


The SNG plant requires much more gas processing than the base case plant which produce an intermediate-Btu gas. This increased complexity can be seen in Figure 23 which shows the additional steps required to go from the raw product gas to the final SNG product for the 500 psig system. After leaving the cyclone where primary separation of particulate material occurs, the gases pass through a sand filter where the rest of the particulates are removed. There is sufficient water vapor in the gas leaving the sand filters to react with $\mathrm{CO}$ via the catalytic water gas shift reactor to increase the $\mathrm{H}_{2} / \mathrm{CO}$ ratio to the $3 / 1$ needed for methanation. The $\mathrm{CO}_{2}$ in the gas after shift is removed in the acid gas removal system. The $\mathrm{CH}_{4}$, $\mathrm{H}_{2}$, $\mathrm{CO}$ mixture then goes through a sulfur guard system to reduce the sulfur down to $0.1 \mathrm{ppm}$ which is required to protect conventional metnanation catalysts. The methanation system employs three stages with intermediate heat removal. The product gas from the methanation system is then compressed to. 1000 psig, dried, and fed into a natural gas transmission line. Stream flow rates, compositions, pressures and temperatures in various parts of the system are tabulated in Table 7. The 100 psig case is basically the same except the 100 psig gas is compressed to 500 psig before gas purification and methanation.

For the SNG case the overall thermal efflciency defined (Total Btu in Product Gas)/(Total Btu in Wood to Plant) is 72.8 percent.

For the 500 psig SNG case the total plant investment is shown in Table 8, the total capital requirements in Table 9, and the annual operating costs in Table 10 .

\section{Estimation of Gas Price}

Total capital requirements for other cases as well as the annual operating costs are listed in Table 11. The capital requirements to produce SNG are lower at 100 psig because the increased cost of lockhoppering at 500 psig doubles the cost of the feed systen. 


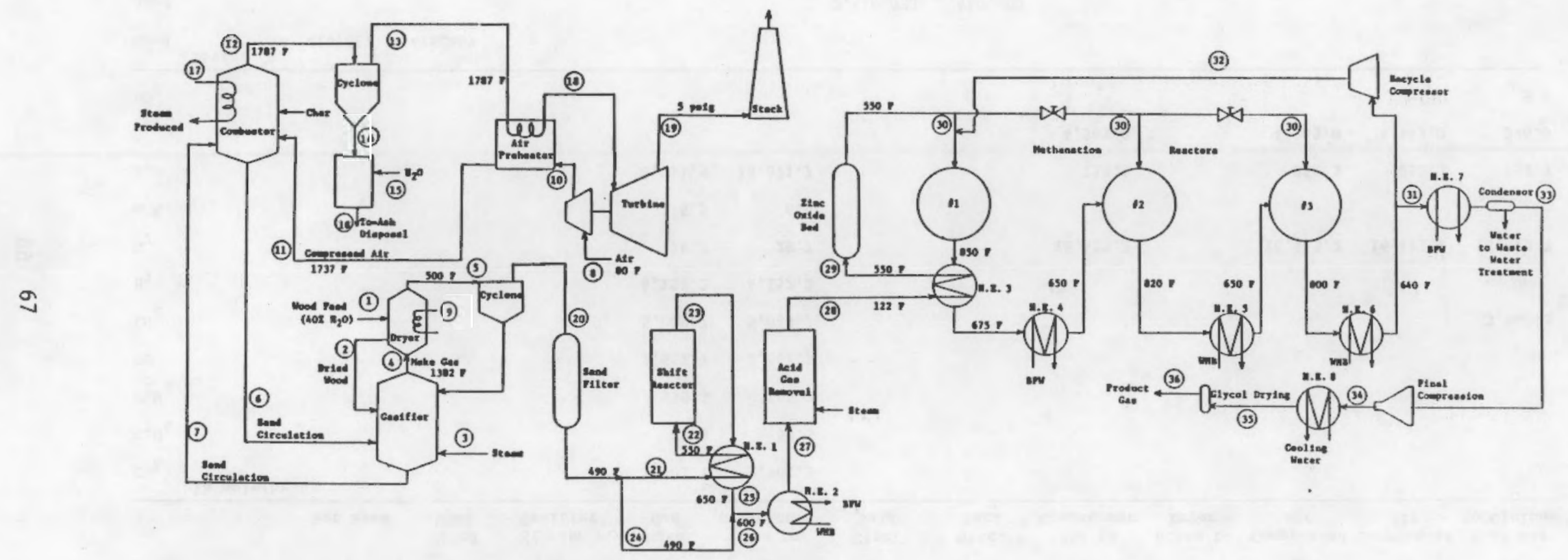

FIGURE 23. PROCESS FLOWSHEET FOR GASIFICATION OF FOREST RESIDUES AND CONVERSION TO SNG 
TABLE 7. MATERIAL BALANCE FOR 5000 TPD HIGH BTU GASIFICATION PLANT

\begin{tabular}{|c|c|c|c|c|c|c|c|c|c|c|c|c|}
\hline & $\begin{array}{c}1 \\
\text { Wet Feed }\end{array}$ & $\begin{array}{c}2 \\
\text { Dried } \\
\text { Hood }\end{array}$ & $\begin{array}{l}3 \\
\text { Steam to } \\
\text { Gaulfier }\end{array}$ & $\begin{array}{l}4 \\
\text { Make } \\
\text { Gas }\end{array}$ & $\begin{array}{c}5 \\
\text { Gas to } \\
\text { Cyclone }\end{array}$ & $\begin{array}{c}6 \\
\text { C1rc. } \\
\text { Sand }\end{array}$ & $\begin{array}{c}7 \\
\text { c1rc. } \\
\text { Sand }\end{array}$ & $\begin{array}{c}\text { B } \\
\text { Air to } \\
\text { Compressor }\end{array}$ & $\begin{array}{c}9 \\
\text { Stean to } \\
\text { Dryer }\end{array}$ & $\begin{array}{c}10 \\
\text { Compressed } \\
\text { Air }\end{array}$ & $\begin{array}{c}11 \\
\text { Compressed } \\
\mathbf{A 1 r}\end{array}$ & $\begin{array}{c}12 \\
\text { Flue Gas } \\
\text { to Cyclone }\end{array}$ \\
\hline $\mathrm{CH}_{4} \quad 1 \mathrm{~b}=010 / \mathrm{hr}$ & & & & $3,901.1$ & $3,901.1$ & & & & & & & \\
\hline $\mathrm{C}_{2} \mathrm{H}_{4}$ & & & & 50.3 & 50.3 & & & & & & & \\
\hline$c_{2} \mathrm{H}_{6}$ & & & & 556.3 & 556.3 & & & & & & & \\
\hline co & & & & $2,661.7$ & $2,661.7$ & & & & & & & \\
\hline $\mathrm{CO}_{2}$ & & & & $5,069.7$ & $5,069.7$ & & & & & & & 3.960 .5 \\
\hline $\mathrm{H}_{2}$ & & & & $4,152.2$ & $4,152.2$ & & & & & & & \\
\hline $\mathrm{H}_{2}$ & & & & 29.7 & 29.7 & & & $16,413.2$ & & $16,413.2$ & $16,413.2$ & $16,413.2$ \\
\hline $\mathrm{H}_{2} \mathrm{~S}$ & & & & 6.5 & 6.5 & & & & & & & \\
\hline $\mathrm{H}_{2} \mathrm{O}$ & & & & $6,011.6$ & $18,871.7$ & & & 252.3 & & 252.3 & 252.3 & 252.3 \\
\hline $\mathrm{O}_{2}$ & & & & & & & & $4,363.0$ & & $4,363.0$ & $4,363.0$ & 396.6 \\
\hline $\mathrm{SO}_{2}$ & & & & & & & & & & & & 5.9 \\
\hline Wood $1 \mathrm{~b}=/ \mathrm{hx}$ & 416,667 & 416,667 & & & & & & & & & & \\
\hline Sand & & & & & & $2,410,000$ & $2,410,000$ & & & & & \\
\hline Ash & & & & & & & & & & & & \\
\hline Carbon & & & & & & & & & & & & \\
\hline $\mathrm{H}_{2} \mathrm{O}$ & 277.778 & 46,296 & 108,292 & & & & & & 170,946 & & & \\
\hline Temperature ( $\mathbf{P})$ & 80 & 500 & 1,000 & 1,382 & 500 & 1,787 & 1,382 & 80 & 1,000 & & & \\
\hline Pressure (pala) & 14.7 & 515 & 1,025 & 515 & 515 & 515 & 515 & 14.7 & 1,025 & & & \\
\hline
\end{tabular}


TABLE 7. (cont1nued)

\begin{tabular}{|c|c|c|c|c|c|c|c|c|c|c|c|c|}
\hline & $\begin{array}{c}13 \\
\text { Tlue Gas to } \\
\text { Preheater }\end{array}$ & 14 & $\begin{array}{c}15 \\
\text { Wuter to } \\
\text { Aeh Diapousl }\end{array}$ & $\begin{array}{c}16 \\
\text { Aeh } \\
\text { D1apoes1 }\end{array}$ & $\begin{array}{c}17 \\
\text { Steana } \\
\text { Produced }\end{array}$ & $\begin{array}{c}18 \\
\text { Flue Gag } \\
\text { to Turb1ae }\end{array}$ & 19 & $\begin{array}{c}20 \\
\text { Gas to } \\
\text { Sand F11ter }\end{array}$ & 21 & 22 & 23 & 24 \\
\hline $\mathrm{CH}_{4} \quad \mathrm{bb}-01 \mathrm{a} / \mathrm{hr}$ & & & & & & & & $3,901.1$ & 2.882 .9 & $2,882.9$ & $2,882.9$ & $1,018.2$ \\
\hline$c_{2} \mathbf{B}_{4}$ & & & & & & & & 50.3 & 37.2 & 37.2 & 37.2 & 13.1 \\
\hline$c_{2}{ }_{6}$ & & & & & & & & 556.3 & 411.1 & 411.1 & 411.1 & 145.2 \\
\hline$c 0$ & & & & & & & & $2,661.7$ & $1,966,9$ & $1,966.9$ & 983.5 & 694.8 \\
\hline $\mathrm{CO}_{2}$ & $3,960.5$ & & & & & 3.960 .5 & $3,960.9$ & 9.069 .7 & $3,746.5$ & $3,746.5$ & 4.729 .9 & $1,323.2$ \\
\hline$H_{2}$ & & & & & & & & $4,152.2$ & $3,068.5$ & $3,068.5$ & $4,051.9$ & $1,083.7$ \\
\hline $\mathbb{H}_{2}$ & $16,413.2$ & & & & & $16,413.2$ & $16,413.2$ & 29.2 & 21.9 & 21.9 & 21.9 & 7.8 \\
\hline $\mathrm{H}_{2} \mathrm{~S}$ & & & & & & & & 6.5 & 4.8 & 4.8 & 4.8 & 1.7 \\
\hline $\mathrm{H}_{2} \mathrm{O}$ & 252.3 & & & & & 252.3 & 252.3 & $18,871.7$ & $13,946.2$ & $13,946.2$ & 13.962 .8 & $4,925,5$ \\
\hline $0_{2}$ & 396.6 & & & & & 396.6 & 396.6 & & & & & \\
\hline $\mathrm{SO}_{2}$ & 5.9 & & & & & 5.9 & 5.9 & & & & & \\
\hline $\begin{array}{ll}\text { Wood } & 1 \mathrm{bs} / \mathrm{hr} \\
\text { Sand } & \end{array}$ & & & & & & & & & & & & \\
\hline Ash & & 19,875 & & 19,875 & & & & & & & & \\
\hline Carbon & & & & & & & & & & & & \\
\hline $\mathrm{M}_{2} \mathrm{O}$ & & & 41,918 & 41,918 & 806,258 & & & & & & & \\
\hline Temperature $(F)$ & 1,787 & 1,787 & 80 & 100 & 1,000 & 1,150 & 255 & 500 & 490 & 550 & 700 & 490 \\
\hline Prensure (paia) & 500 & 500 & 14.7 & 14.7 & 1,025 & 500 & 20 & 510 & 500 & 500 & 500 & 500 \\
\hline
\end{tabular}


TABLE 7. (continued)

\begin{tabular}{|c|c|c|c|c|c|c|c|c|c|c|c|c|}
\hline & 25 & 26 & 27 & 28 & 29 & 30 & 31 & 32 & 33 & 34 & 35 & 36 \\
\hline $\mathrm{CH}_{4} \mathrm{Ib} \operatorname{mole} / \mathrm{hr}$ & $2,892.9$ & $3,901.1$ & $3,901.1$ & $3,901.1$ & $3,901.1$ & $1,300.4$ & $5,578.2$ & $11,156.4$ & $5,378.2$ & $5,578.2$ & $5,578.2$ & $5,578.2$ \\
\hline$C_{2} B_{4}$ & 37.2 & 50.3 & 30.3 & 30.3 & 50.3 & 16.8 & 50.4 & 100.8 & 50.4 & 50.4 & 50.4 & 50.4 \\
\hline$c_{2} \mathrm{~g}_{6}$ & 411.1 & 556.3 & 356.3 & 556.3 & 556.3 & 185.4 & 556.3 & $1,112.4$ & 556.3 & 556.3 & 556.3 & 556.3 \\
\hline co & 983.9 & $1,678.3$ & $1,678.3$ & $1,678.3$ & $1,578.3$ & 559.4 & - & -- & -- & -- & -- & -- \\
\hline $\mathrm{CO}_{2}$ & 4.729 .9 & $6,053.1$ & $0,053.1$ & 2.3 & 2.3 & 0.8 & 2.3 & 4.8 & 2.3 & 2.3 & 2.3 & 2.3 \\
\hline$H_{2}$ & $4,051.9$ & 9.135 .6 & $5,135.6$ & $3,129.6$ & $5,229.6$ & $1,709.9$ & 94.8 & 189.6 & 94.8 & 94.8 & 94.8 & 94.8 \\
\hline $\mathrm{H}_{2}$ & 21.9 & 29.7 & 29.7 & 29.7 & 29.7 & 9.9 & 29.7 & 59.4 & 29.7 & 29.7 & 29.7 & 29.7 \\
\hline $\mathrm{H}_{2} \mathrm{~s}$ & 4.8 & 6.5 & 6.5 & -- & - & - & -- & - & -- & - & -- & -- \\
\hline $\mathrm{H}_{2} \mathrm{O}$ & $12,962.8$ & $17,888.3$ & $1,038.5$ & 51.2 & 51.2 & 17.1 & $1,729.5$ & 3.459 .0 & 31.9 & 31.9 & 7.4 & - \\
\hline \multicolumn{6}{|l|}{$\mathrm{so}_{2}$} & \multicolumn{7}{|c|}{$o_{2}$} \\
\hline \multicolumn{13}{|l|}{ Hood $1 \mathrm{bs} / \mathrm{hr}$} \\
\hline \multicolumn{13}{|l|}{ Sand } \\
\hline \multicolumn{13}{|l|}{ Ash } \\
\hline \multicolumn{13}{|l|}{ Carbon } \\
\hline \multicolumn{13}{|l|}{$\mathrm{H}_{2} \mathrm{O}$} \\
\hline Temperature $(p)$ & 650 & 600 & 250 & 222 & 550 & 550 & 640 & 650 & 125 & 264 & 100 & 100 \\
\hline Pressure (psia) & 500 & 500 & 500 & 495 & 490 & 490 & 480 & 490 & 480 & 1,015 & 1,015 & 1,010 \\
\hline
\end{tabular}


TABLE 8. TOTAL PLANT INVESTMENT - SNG

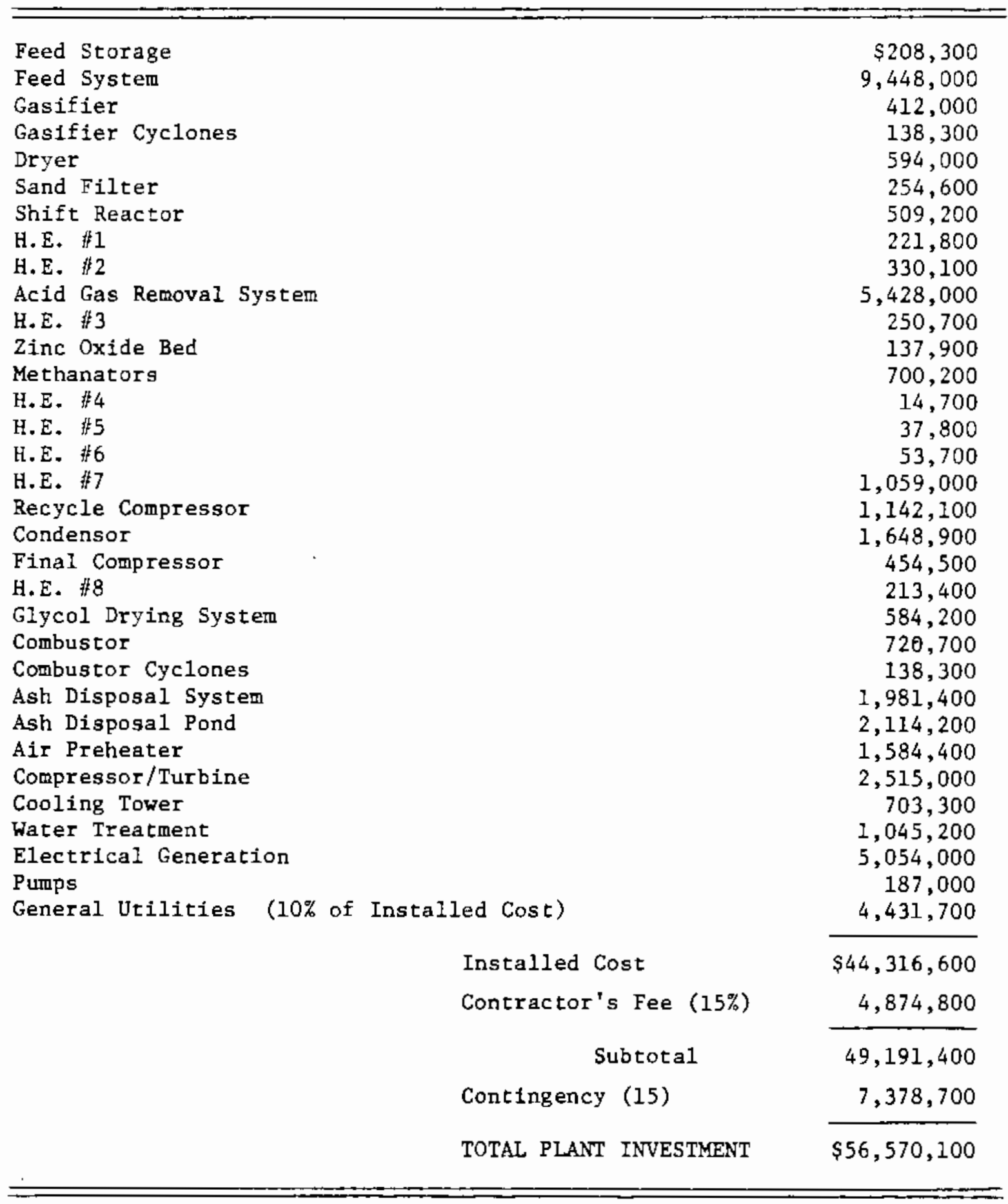


TABLE 9. TOTAL CAPITAL REQUIREMENT - SNG

\begin{tabular}{|c|c|}
\hline Total Plant Investment & $\$ 56,570,100$ \\
\hline $\begin{array}{l}\text { Allowance for Funds Used During Construction } \\
\quad(\text { T.P.I. } x 3 \text { yrs } x 0.09)\end{array}$ & $15,273,900$ \\
\hline $\begin{array}{l}\text { Startup Costs ( } 20 \% \text { total annual gross } \\
\text { operating costs) }\end{array}$ & $7,767,500$ \\
\hline \multicolumn{2}{|l|}{ Working Capttal } \\
\hline $\begin{array}{l}\text { 1) Raw materlals ( } 14 \text {-day inventory) } \\
\text { 2) Materlals and supplies (0.9\% T.P.I.) } \\
\text { 3) Net receivables ( } 1 / 24 \text { annul gas revenue) } \\
\text { (by-product revenue from surplus electricity) }\end{array}$ & $\begin{array}{r}1,166,700 \\
509,100 \\
2,294,000 \\
733,800\end{array}$ \\
\hline TOTAL CAPITAL REQUIREMENT & $\$ 84,315,100$ \\
\hline
\end{tabular}


TABLE 10. ANNUAL OPERATING COSTS -SNG

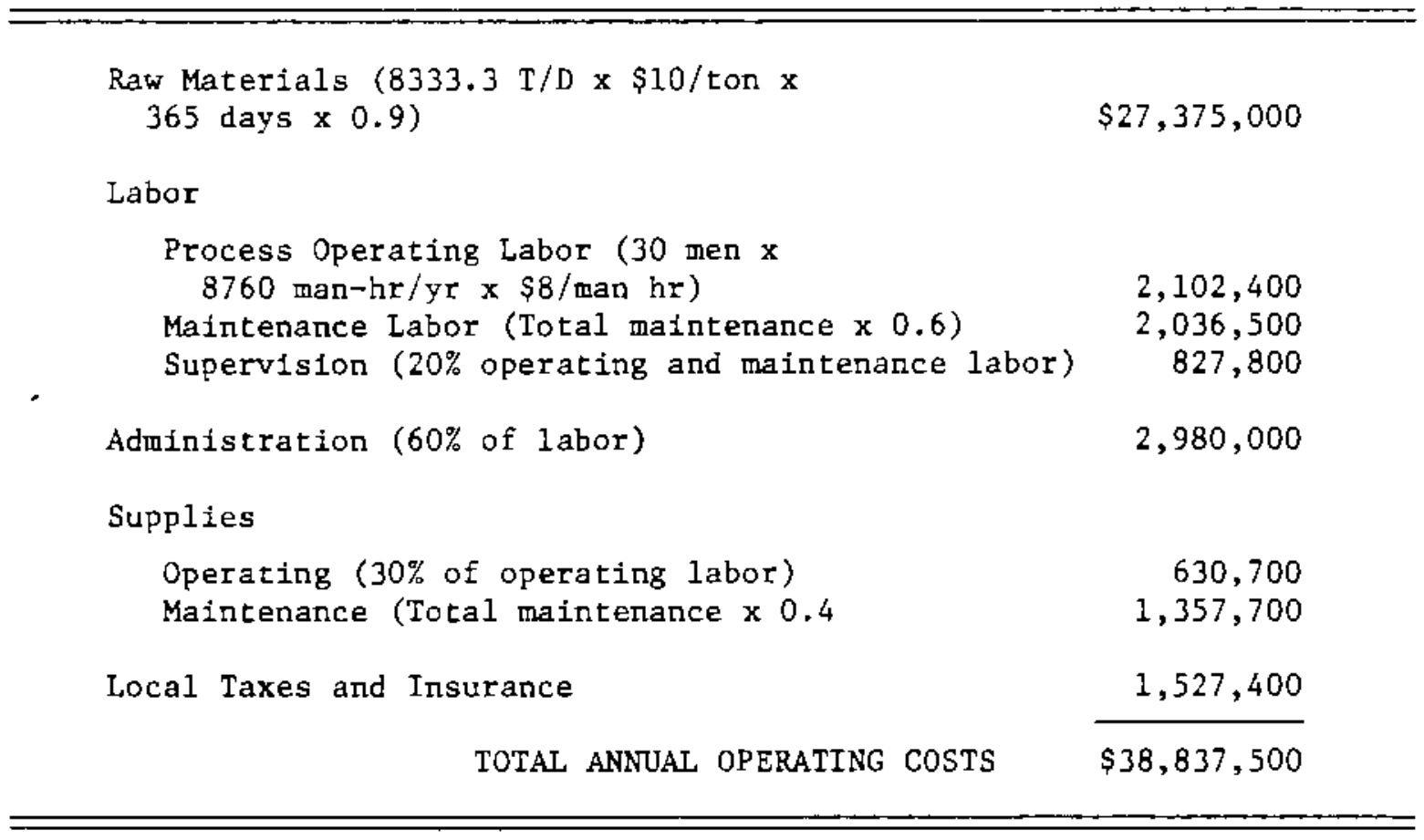


TABLE 11. CAPITAL REQUIREMENTS AND ANNUAL OPERATING COST SUMMARY PLANT PRESSURE $=100$ PSIG EXCEPT WHERE NOTED

\begin{tabular}{|c|c|c|}
\hline $\begin{array}{c}\text { Plant Size/Gaseous Product } \\
\text { (tons/day) }\end{array}$ & $\begin{array}{l}\text { Total Capital Requirements } \\
\text { (millions of dollars) }\end{array}$ & $\begin{array}{l}\text { Annual Operating Cost* } \\
\text { (m1111ons of dollars) }\end{array}$ \\
\hline $500 \mathrm{tpd} /$ Unquenched, Intermediate-Btu Gas & 8.8 & 5.4 \\
\hline $1000 \mathrm{tpd} /$ Unquenhed, Intermediate-Btu Gas & 14.2 & 8.3 \\
\hline $1000 \mathrm{tpd} /$ Quenched, Intermediate-Btu Gas & 16.7 & 9.2 \\
\hline $5000 \mathrm{tpd} / \mathrm{SNG}, 500 \mathrm{pstg}$ & 84.3 & 38.8 \\
\hline $\begin{array}{l}5000 \mathrm{tpd} / \mathrm{SNG}, 100 \mathrm{psig} \text {, Intermediate } \\
\text { Compression }\end{array}$ & 80.7 & 38.5 \\
\hline
\end{tabular}

*Based on green ( 40 percent molsture) wood at $\$ 10 /$ ton. 
The gas prices were calculated from the preceding cost information using standard utility financing and are the average gas prices over the assumed 20 year plant life.

The average utlity gas prices for the various process options are listed in Table 12 for green wood prices of $\$ 10$ and $\$ 20 / t o n$. (A wood price of $\$ 10 /$ green ton is approximately $\$ I / M M B t u$.

The sensttlvity of gas price to wood price shows the importance of reducing the front end sollds preparation costs if the gas prices are to be minimized.

For comparison purposes, the approximate prices of other supplemental clean fuels are given below:

$\begin{array}{ll}\text { SNG from coal } & \$ 4.00 / \mathrm{MM} \mathrm{Btu} \\ \text { No. } 2 \text { heating oil } & 2.70 / \mathrm{MM} \mathrm{Btu} \\ \text { LNG } & 3.00 / \mathrm{MM} \mathrm{Btu}\end{array}$

The average gas prices for the above cases are shown graphically for easter visualization in Figure 24 which also shows the prices of the above supplemental fuels that would compete with gas from wood.

Thus, in many areas of the country the production of a clean transportable gas from wood should be cost competitive with other fuels now. In addition, gas from wood would reduce the need for imported oil and LNG and, because of the renewable nature of the resource, provide a long-term dependable source of energy. 
TABLE 12. AVERAGE GAS PRICE*

\begin{tabular}{|c|c|c|c|}
\hline \multirow{2}{*}{$\begin{array}{l}\text { Plant Size, } \\
\text { tons/day }\end{array}$} & \multirow[b]{2}{*}{ Gas Product } & \multicolumn{2}{|c|}{ Gas Price } \\
\hline & & $\$ 10 /$ ton & $\$ 20 /$ ton \\
\hline 500 & Quenched-350 Btu/SCF & 2.93 & 4.02 \\
\hline 1000 & Quenched-350 Btu/SCF & 2.34 & 3.53 \\
\hline 1000 & Hot-350 Btu/SCE & 2.09 & 3.29 \\
\hline 5000 & SNG & $2.4 i$ & 3.83 \\
\hline \multicolumn{4}{|c|}{$\begin{array}{l}\text { "Based on utility financing with the following financial } \\
\text { factors. }\end{array}$} \\
\hline \multicolumn{4}{|c|}{$\begin{array}{l}\text { 20-year project life } \\
\text { 20-year straight line depteclation on plant investment, } \\
\quad \text { allowance for funds used during construction, } \\
\quad \text { captlalized start-up costs } \\
\text { Debt/equity ratio }=75 / 25 \\
9 \% \text { interest in debt } \\
15 \% \text { return on equity } \\
48 \% \text { Federal Income Tax }\end{array}$} \\
\hline
\end{tabular}




\section{WOOD PRICE RANGE \\ $\$ 10$ TO \$20/GREEN TON}

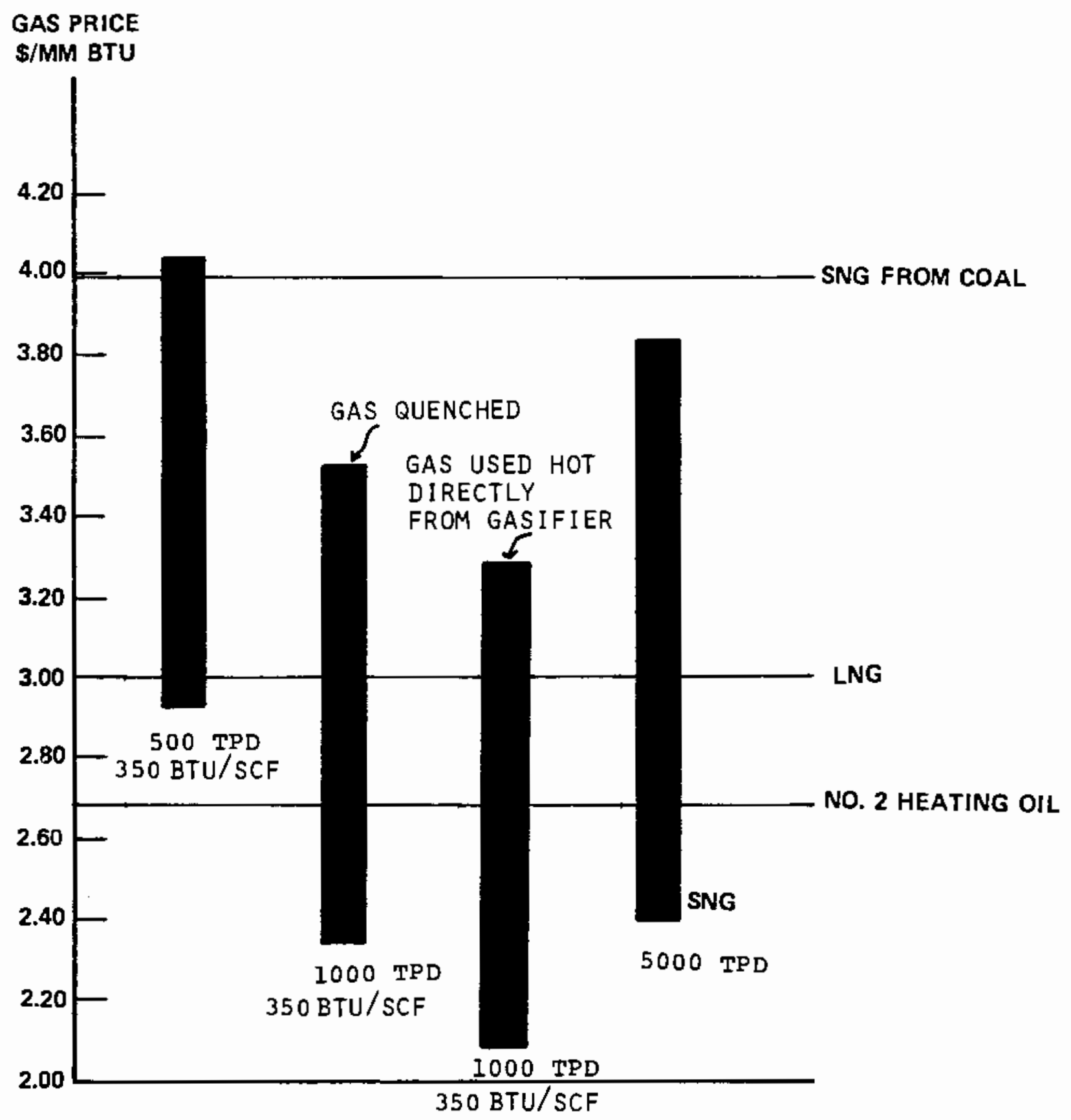

FIGURE 24. EFFECT OF PLANT SIZE, WOOD PRICE, GAS HEATING VALUE, AND GAS QUENCHING ON AVERAGE PRICE OF GAS FROM WOOD 


\section{PROJECT TEAM}

\section{$\underline{\text { Key Staff }}$}

S. A. Barker

S. P. Chauhan

H. N. Conkle

L. M. Curran

H. F. Feldmann

K. T. LAu

J. R. Longanbach

Program Manager

H. F. Feldmann Manager

Synthet1c Fuels Program Office

DOE Program Manager

N. De1Gobbo

Chtef

Fuels from Blomass Systems Branch 


\section{REFERENCES}

(1) Chauhan, S. P., H. F. Feldmann, E. P. Stambaugh and J. H. Oxley, "A Novel Approach to Gasification of Coal Using Chemically Incorporated Catalysts", presented at the 173rd Nacional Meecing of the American Chemical Society (Fuel Chemlstry Division), New Orleans, Louisiana (March 1977).

(2) Baille, R. C. and S. B. Alpert, Conversion of Municlpal Waste to a Substicute Fue1, Public Works for August 1973, p 76-79, 98. 
.

- 
No. of

Copies

OFFSITE

Simon Friedrich

Biomass Energy Technology Division

Forrestal Building ( $C E-321$ )

U.S. Department of Energy

1000 Independence Avenue

Washington, DC 20585

30 DOE Technical Information Center

Onsite

DOE Richland Operations

D. R. Segna

10 Pactfic Northwest Laboratory

G. F. Schiefelbein

D. J. Stevens

M. A. Gerber

Publishing Coordination (2)

Technical Information (5) 
